\title{
Melatonin: One molecule one- medicine for many diseases, coronavirus (SARS-CoV-2) disease (Covid- 19); Function in plants
}

\author{
Ravindra B. Malabadi ${ }^{*}$, Kiran P. Kolkar ${ }^{2}$, Neelambika T. Meti ${ }^{3}$, Raju K. Chalannavar ${ }^{4}$ \\ ${ }^{1 *}{ }^{4}$ Department of Applied Botany, Mangalore University, Mangalagangotri-574199, Mangalore, Karnataka State, India \\ ${ }^{2}$ Department of Botany, Karnatak Science College, Dharwad, Karnataka state, India \\ ${ }^{3}$ Plant Biotechnology Laboratory, Rajiv Gandhi Institute of IT and Biotechnology, Bharati Vidyapeeth University, Pune-Satara \\ Road, Katraj, Pune - 411046, Maharashtra State, India \\ Corresponding author* \\ DOI: https://dx.doi.org/10.51244/IJRSI.2021.8310
}

\begin{abstract}
This review paper highlights the role of melatonin in many diseases, coronavirus (SARS-CoV-2) disease (covid-19) and multi-physiological functions in plants. Based on its ubiquitous distribution (animal, human, plant, fungi, bacteria, algae), and multi-directional activity, melatonin is recommended as one of the most versatile biological signal of nature. Melatonin, so called a Hormone of darkness, has a high safety profile and potential to be used as COVID-19 therapy. Melatonin is a light sensitive molecule used in the therapy of sleeping disorders- insomnia, glaucoma, stroke, cancers, puberty, Alzheimers disease, Parkinson disease, ultraviolet light skin damage protection, thrombocytopenia, in smoking cessation, headache protection, migrane, and as an antioxidant. Melotonin is present in different parts of all the plant species studied, including leaves, stems, roots, fruits and seeds. Melatonin plays an important aspect to regulate the several physiological role of plants viz. circadian regulator, cytoprotector, growth promoter, antioxidant and free radical scavenger. In plants, melatonin also promotes rhizogenesis, cellular expansion and provide defense against environmental stress condition. Melatonin aids plants in terms of root growth, leaf morphology, chlorophyll preservation and fruit development.
\end{abstract}

Keywords: Coronavirus, herbal medine, hormone of darkness, light sensitive, phytomelatonin, signal molecule, SARS-CoV-2

\section{INTRODUCTION}

$\mathrm{M}$ elatonin was first discovered in 1958 from the bovine pineal gland of cattle and identified as N-acetyl-5methoxy-tryptamine by Lerner and coworkers (Lerner et al., 1958; Arnao and Hernández-Ruiz, 2006). Melatonin is an evolutionarily conserved molecule that serves a time-keeping function in various species (Zawilska et al., 2009; Arnao and Hernández-Ruiz, 2006). Melatonin seems to be a ubiquitous molecule in the living world. In 1959, melatonin was detected in humans (Lerner et al., 1959; Arnao and Hernández-Ruiz, 2006). Later in the 1960s and 1970s, melatonin was detected in many mammals and vertebrates such as birds, amphibians, and fish (Arnao, 2014; Arnao and Hernández-Ruiz, 2006, 2007a, 2007b, 2008, 2015; Fan et al., 2018; Hardeland, 2016; Hernandez-Ruiz et al., 2005). It was named melatonin because of its ability in certain fish, reptiles and amphibians to lighten skin (Arnao and Hernández-Ruiz, 2006; Tan et al., 2007; Cardinali et al., 1997). In mammals, melatonin is secreted from the pineal gland at night, from where it diffuses into the cerebro-spinal fluid and the blood stream, although levels quickly drop during the day (Arnao and Hernández-Ruiz, 2006). In 1991, melatonin was detected in the unicellular algae Gonyaulax polyedra and, later, in other dinoflagellates and green algae (Balzer and Hardeland, 1991; Hardeland and Fuhrberg, 1996; Fuhrberg et al., 1996; Arnao and HernándezRuiz, 2006). Melatonin was also detected in few bacteria and fungi (Hardeland and Poeggeler, 2003; Arnao and HernándezRuiz, 2006). In the 1980s, melatonin was discovered in invertebrates such as planarians, annelids, molluscs, insects, and crustaceans, among others (Arnao and Hernández-Ruiz, 2006; Arnao, 2014; Arnao and Hernández-Ruiz, 2015; Tan et al., 2007; Cardinali et al., 1997).

The melatonin levels increases in night in human body leading to a quality sleep and decreases in day time since melatonin is light sensitive (Brzezinski, 1997; Arnao and Hernández-Ruiz, 2006; West et al., 2011; Ayushi and Maheep, 2007; Arnao and Hernández-Ruiz, 2006). Therefore, melatonin is known as a biological modulator of mood, sleep, retina physiology, sexual behaviour, seasonal reproductive physiology, circadian rhythms and immunological enhancement (Haldar and Ahmad, 2010; Brzezinski, 1997; Arnao and Hernández-Ruiz, 2006; West et al., 2011; Pandi-Perumal et al., 2006; Reiter et al., 2016). The seasons, and daily physical rhythms can have a profound effect on the physiology of the living organism, which includes immune status. The immune system can be influenced by a variety of signals and one of them is photic stimulus (Pandi-Perumal et al., 2006; Reiter et al., 2016; Arnao and Hernández-Ruiz, 2006). Light may regulate the immunity through the neuroendocrine system leading to the most recent branch of research the "Photoimmunomodulation" (Haldar and Ahmad, 2010; Tan et al., 2007; Cardinali et al., 1997; Pandi-Perumal et al., 2006; Reiter et al., 2016; Arnao and Hernández-Ruiz, 2006). The functions of melatonin include the chemical expression of darkness in vertebrates, environmental tolerance in fungi and 
plants, sexual signaling in birds and fish, seasonal reproductive regulation in photoperiodic mammals, and immunomodulation and anti-inflammatory activity in all vertebrates tested high melatonin levels could be served as a signal of vitality and health (Arnao and Hernández-Ruiz, 2006; Haldar and Ahmad, 2010; Tan et al., 2007; Cardinali et al., 1997; Pandi-Perumal et al., 2006; Reiter et al., 2016).

The importance of melatonin is also highlighted as its scavenging capacity (antioxidant activity) against biological free radicals, such as reactive oxygen and nitrogen species, including the hydroxyl radical, singlet oxygen, peroxyl radical, hydrogen peroxide, peroxynitrite anion and nitric oxide (Pandi-Perumal et al., 2006; Reiter et al., 2016; Arnao and Hernández-Ruiz, 2006; Tan et al., 1993). Melatonin is produced in mammals in the pineal gland and regulates circadian rhythm, sleep cycles, and seasonal reproduction (Lang, 2008; Wu and Swaab., 2005; Tekbas et al., 2008; Tengattini et al., 2008; Tan et al., 2007; Cardinali et al., 1997; Morera and Abreu, 2006; Nunes and Pereira, 2008; Arnao and Hernández-Ruiz, 2006). Melatonin, or N-acetyl-5methoxy-tryptamine, an indole mainly produced in the pineal gland, has been shown to have potent endogenous antioxidant actions (Mayo et al., 2005; Zawilska et al., 2009; Arnao and Hernández-Ruiz, 2006, 2007a, 2007b, 2008, 2015; Arnao, 2014; Fan et al., 2018; Hardeland, 2016; Hernandez-Ruiz et al., 2005). In vertebrates, melatonin is produced predominantly by the pineal gland with a marked circadian rhythm that is governed by the central circadian pacemaker (biological clock) in the suprachiasmatic nuclei of the hypothalamus (Zawilska et al., 2009). High levels of melatonin are normally found at night, and low levels are seen during daylight hours. As a consequence, melatonin has been called the "Hormone of darkness (Zawilska et al., 2009; Pandi-Perumal et al., 2006; Reiter et al., 2016; Arnao and Hernández-Ruiz, 2006, 2007a, 2007b, 2008, 2015; Arnao, 2014; Fan et al., 2018; Hardeland, 2016; Hernandez-Ruiz et al., 2005).

The biosynthetic pathway of melatonin has been clearly determined in mammals, including humans, and other groups (amphibian, reptilian, avian) (Hardeland et al., 1993; Sugden, 1989; Yu and Reiter, 1993; Foulkes et al., 1997; Arnao and Hernández-Ruiz, 2006, 2007a, 2007b, 2008, 2015; Arnao, 2014; Fan et al., 2018; Hardeland, 2016; Hernandez-Ruiz et al., 2005). The biosynthesis of melatonin and IAA presents some common precursors, such as tryptophan and tryptamine. Melatonin is synthetized from serotonin (5-hydroxy tryptamine) via an acetylation reaction catalyzed by arylalkylamine $\mathrm{N}$-acetyltransferase, also called serotonin $\mathrm{N}$ acetyltransferase (NAT) (EC 2.3.1.87), a regulated enzyme that controls melatonin biosynthesis (Arnao and HernándezRuiz, 2006; Forsyth, 2020; Murch et al., 2000; Murch et al., 2001; Murch and Saxena, 2002; Murch et al., 1997; Erland and Saxena, 2018; Erland et al., 2018a, 2018b, 2018c). Exposure of melatonin to light resulted in the decreased level of circulating melatonin. Melatonin is decreased by $50 \%$ after
39 minutes of exposure to incandescent light at night (Nunes and Pereira 2008; Lang, 2008; Arnao and Hernández-Ruiz, 2006). Melatonin is a light sensitive molecule. It absorbs light at $254 \mathrm{~nm}$ and thus is susceptible to UV degradation (Maharaj et al. 2002; Lang, 2008; Arnao and Hernández-Ruiz, 2006). The diurnal regulation of melatonin has many different roles which also includes that of potent antioxidant and free radical scavenger, potential anti-inflammatory agent, immunomodulatory agent, and inhibitor of carcinogenesis (Arnao and Hernández-Ruiz, 2006; Lang, 2008; Wu and Swaab., 2005; Tekbas et al., 2008; Tengattini et al., 2008; Tan et al., 2007; Cardinali et al., 1997; Morera and Abreu, 2006; Nunes and Pereira, 2008). A decrease in melatonin level leads to metabolic disruption, increased oxidative stress, reduced immune function, increased risk of cancer, and changes in reproduction (Lang, 2008; Wu and Swaab., 2005; Tekbas et al., 2008; Tengattini et al., 2008; Tan et al., 2007; Cardinali et al., 1997; Morera and Abreu, 2006; Nunes and Pereira, 2008; Arnao and Hernández-Ruiz, 2006).

This concise review will endeavor to provide an overview of melatonin used as a medicine in controlling many diseses, including deadly coronavirus (SARS-CoV-2) outbreak and probable role in plant growth and regulation.

\section{MELATONIN: ONE MOLECULE- ONE MEDICINE FOR MANY DISEASES}

1. In humans, melatonin production decreases with age. As age increases, oxidative disease risk also increases resulted in the short memory loss (Dementia) or Alzheimers disease. Parkinson's disease (PD) is the second most common neurodegenerative disorder after Alzheimer's disease (Mayo et al., 2005). The neurodegenerative disorders are mainly caused by oxidative damage, melatonin has been tested successfully in both in vivo and in vitro models of Parkinson's disease (PD) (Mayo et al., 2005; Arnao and Hernández-Ruiz, 2006). Therefore, the potential use of melatonin as a therapy for oxidative disease treatment or prevention has been reported (Wu and Swaab, 2005; Arnao and Hernández-Ruiz, 2006). Wu and Swaab, (2005) have studied the effects of light therapy and melatonin supplementation as a means of treating Alzheimers disease (Wu and Swaab., 2005; Lang, 2008; PandiPerumal et al., 2006; Arnao and Hernández-Ruiz, 2006). They have postulated that the decline in melatonin production with age, which disturbs the sleep/wake pattern and circadian rhythms, may contribute to mental decline (Wu and Swaab, 2005; Lang, 2008; Arnao and Hernández-Ruiz, 2006). Alzheimers, cardiovascular disease, and cancer are all oxidative diseases and the primary evidence of the benefits of melatonin in these systems adds to the interest of surrounding melatonin (Venkatramanujam, 2011;Lang, 2008; Wu and Swaab., 2005; Tekbas et al., 2008; Tengattini et al., 
2008; Tan et al., 2007; Cardinali et al., 1997; Morera and Abreu, 2006; Nunes and Pereira, 2008).

2. Melatonin is an indoleamine secreted by the pineal gland as well as a plant-derived product, and resveratrol (RSV) is a naturally occurring polyphenol synthesized by a variety of plant species; both molecules act as a neuroprotector and antioxidant (Kwon et al., 2011). Studies repoted by Kwon et al., (2011) have demonstrated that resveratrol (RSV) reduced the incidence of Alzheimers disease and stroke, while melatonin supplementation was found to reduce the progression of the cognitive impairment in Alzheimers disease (Kwon et al., 2011). The heme oxygenase-1 (HO-1) is an inducible and redoxregulated enzyme that provides tissue-specific antioxidant effects. The treatment of MG132 + resveratrol (RSV) mimicked the effects of melatonin + RSV, and melatonin + resveratrol (RSV) inhibited ubiquitination of HO-1(Kwon et al., 2011). These data confirmed that melatonin potentiates the neuroprotective effect of resveratrol (RSV) against oxidative injury, by enhancing $\mathrm{HO}-1$ induction through inhibiting ubiquitination-dependent proteasome pathway, which may provide an effective means to treat the neurodegenerative disorders (Kwon et al., 2011).

3. 2) It is speculated that melatonin may play a role in determining the onset of puberty and lifestyle changes may be influencing melatonin levels, thus causing earlier onset of puberty in girls (Yun et al., 2004; Murcia, 2002; Lang, 2008). Therefore, if melatonin levels are reduced, it could potentially lead to the early onset of puberty. However, melatonin appears to have a regulatory role within the human reproductive system (Yun et al., 2004; Murcia, 2002; Lang, 2008). Melatonin has also been shown to have antibiotic and antiviral activity (Nunes and Pereira, 2008; Lang, 2008; Arnao and Hernández-Ruiz, 2006).

4. Cyclooxygenase-2(COX-2) is a key enzyme in the inflammatory response system and over-expression is associated with many diseases and cancer (Lang, 2008). Melatonin and its metabolites may regulate COX-2 and have been shown to prevent COX-2 activation. In addition, they prevent the oxidation of inducible nitric oxide synthatase, thus playing an important role in the regulation of the inflammatory response (Arnao and Hernández-Ruiz, 2006; Mayo et al., 2005; Lang, 2008).

5. It is well-known that melatonin as an anti-oxidative and anti-inflammatory agent counters acute lung injury (ALI)/acute respiratory distress syndrome (ARDS) induced by viral and bacterial infections (Juybaria et al., 2020; Zhang et al., 2020). Melatonin can be beneficial in critically ill patients via reducing vessel permeability, inducing sedation, decreasing agitation and increasing sleep quality (Juybaria et al., 2020; Zhang et al., 2020; Lang, 2008).

6. Circadian disruption has been identified as a risk factor for health disorders such as obesity, cardiovascular disease, and cancer (Koritala et al., 2021; Arnao and Hernández-Ruiz, 2006). In functional assessments, the experimental study demonstrated that there was an increased sensitivity to both endogenous and exogenous sources of DNA damage after exposure to simulated night shift (Koritala et al., 2021). These results confirmed that circadian dysregulation of DNA repair may increase DNA damage and potentiate elevated cancer risk in night shift workers (Koritala et al., 2021).

7. The relevant cutaneous effects and mechanisms of melatonin, portray melatonin acts as a major skin protectant and multi-facetted functions of melatonin may impact on skin biology and pathology (Fischer et al., 2008). Therefore, melatonin may become therapeutically exploitable in cutaneous medicine (Fischer et al., 2008; Arnao and Hernández-Ruiz, 2006).

8. One of the study indicated that, a major role of melatonin in the process of temporal integration and binding involve neurons in suprachiasmatic nuclei, specifically targeting the pineal gland and other structures, and control the neuroendocrine rhythms (Bob and Fedor-Freybergh, 2008). Melatonin is an endocrine output signal of the clock and provides circadian information as an endogenous synchronizer which stabilizes and reinforces the circadian rhythms (Bob and Fedor-Freybergh, 2008; Arnao and Hernández-Ruiz, 2006).

9. Stroke also referred to as ischemia/reperfusion, a cerebrovascular accident, or brain attack often has devastating neuropathological, neurophysiological, and biobehavioral consequences that commonly resulted in permanent disability or death (Reiter et al., 2005). Since both stroke and heart attack are very serious conditions that have marked individual and societal consequences, the use of melatonin to potentially protect against these conditions should be seriously considered (Reiter et al., 2005; Arnao and Hernández-Ruiz, 2006). The fact that melatonin is an endogenously produced molecule should enhance its safety, given that it is not a foreign substance in the body (Reiter et al., 2005). Many studies have examined pharmacological doses of melatonin, acutely and chronically in both mammals and humans, as to its toxicity (Reiter et al., 2005; Arnao and Hernández-Ruiz, 2006). Certain individuals are at increased risk for neurological stroke; this group 
includes individuals with hypertension, atherosclerosis, heart disease and other cardiovascular disorders, and those who smoke cigarettes (Reiter et al., 2005). Also, obesity, advanced age, and diabetes mellitus are well-known risk factors for stroke (Reiter et al., 2005). On the basis of evidence it is confirmed that endogenously produced and exogenously administered melatonin reduced the degree of tissue damage and limits the biobehavioral deficits associated with experimental models of schemia/reperfusion injury in the brain (i.e., stroke) (Reiter et al., 2005). Melatonin's efficacy in curtailing neural damage under conditions of transitory interruption of the blood supply to the brain has been well documented in models of both focal and global ischemia (Reiter et al., 2005). Melatonin reduces neurophysiological deficits, infarct volume, the degree of neural edema, lipid peroxidation, protein carbonyls, DNA damage, neuron and glial loss, and death of the animals (Reiter et al., 2005). Melatonin's protective actions against these adverse changes are believed to stem from its direct free radical scavenging and indirect antioxidant activities, possibly from its ability to limit free radical generation at the mitochondrial level (Reiter et al., 2005).

10. Melatonin is related to its antioxidant effects (Bonnefont-Rousselot and Collin, 2010). Oxidative stress, i.e., an imbalance between the production of reactive oxygen species and antioxidant defences, is involved in several pathological conditions such as cardiovascular or neurological disease, and in aging (Bonnefont-Rousselot and Collin, 2010). Therefore, research for antioxidants has developed. However, classical antioxidants often failed to exhibit beneficial effects, especially in metabolic diseases. Melatonin has been shown as a specific antioxidant due to its amphiphilic feature that allows it to cross physiological barriers, thereby reducing oxidative damage in both lipid and aqueous cell environments (Bonnefont-Rousselot and Collin, 2010). Therapeutic potential of melatonin relies either on increasing melatonin dietary intake or on supplementation with supraphysiological dosages (Bonnefont-Rousselot and Collin, 2010). Clinical trials showed that melatonin could be efficient in preventing cell damage, as well under acute (sepsis, asphyxia in newborns) as under chronic (metabolic and neurodegenerative diseases, cancer, inflammation, aging) (Bonnefont-Rousselot and Collin, 2010). Its global action on oxidative stress, together with its rhythmicity that plays a role in several metabolic functions, lead melatonin to be of great interest for future clinical research in order to improve public health (Bonnefont-Rousselot and Collin, 2010).
11. Melatonin's actions in several immune pathologies including infection, inflammation, and autoimmunity together with the relation between melatonin, immunity, and cancer (Carrillo-Vico et al., 2005; Arnao and Hernández-Ruiz, 2006).

12. Melatonin synthesis occurs in the retina of most of the animals as well as in humans (Lundmark et al., 2007). In the eye, melatonin is synthesized through the same pathway as that described in the pineal gland. Tryptophan is taken up from the blood and is converted to serotonin. Serotonin is then converted into $\mathrm{N}$-acetyl serotonin by the enzyme arylamine $\mathrm{N}$ acetyl transferase (AA-NAT) (Arnao and HernándezRuiz, 2006). N-acetyl serotonin is converted to melatonin by the enzyme hydroxyindole- O-methyl transferase (HIOMT). The existence of melatonin biosynthetic pathway in the mammalian retina was initially supported by the discovery of retinal HIOMT activity (Lundmark et al., 2007). Circadian oscillators that control retinal melatonin synthesis have been identified in the eyes of different animal species (Lundmark et al., 2007). The presence of melatonin receptors is demonstrable by immunocytochemical studies of ocular tissues (Lundmark et al., 2007). These receptors may have different functional roles in different parts of the eye (Lundmark et al., 2007). Therefore, melatonin is a potent antioxidant molecule, it can be effective in scavenging free radicals that are generated in ocular tissues (Lundmark et al., 2007). By this mechanism, melatonin could protect the ocular tissues against disorders like glaucoma, age-related macular degeneration, retinopathy of prematurity, photokeratitis and cataracts (Lundmark et al., 2007). Although an increased intraocular pressure is an important risk factor in glaucoma, other concomitant phenomena like increased glutamate levels, altered nitric oxide metabolism and increased free radical generation seem to play a significant role in its pathogenesis (Lundmark et al., 2007). Therefore, melatonin, being an efficient antioxidant with antinitridergic properties, has a promising role in the treatment and management of glaucoma (Lundmark et al., 2007).

Besides its well-known regulatory role on circadian rhythm, the pineal gland hormone melatonin has other biological functions and a distinct metabolism in various cell types and peripheral tissues (Luchetti et al., 2010). In different tissues and organs, melatonin has been described to act as a paracrine and also as an intracrine and autocrine agent with overall homeostatic functions and pleiotropic effects that include cell protection and prosurvival factor (Luchetti et al., 2010). These include the role of melatonin as intracrine, autocrine, and/or paracrine factor in key homeostatic functions such as the control of energy metabolism (melatonin essentially acting as 
an anabolic factor), physiological growth, differentiation, and responsiveness to stress stimuli (Luchetti et al., 2010). These latter effects, documented in a number of in vitro and in vivo studies, thus conferring the protection against a number of xenobiotics and endobiotics produced by acute and chronic noxious stimuli (Luchetti et al., 2010). A number of in vitro and in vivo studies clearly demonstrated the character of the cell protection factor of the hormone melatonin (Luchetti et al., 2010). This protection extends to several cell types and tissues and appears to be of particular relevance in neuroprotection and in the control of immuno-inflammatory processes (Luchetti et al., 2010). Melatonin-derived cell protection is clearly associated with specific signaling and with the transcription of metabolic and stress-related genes (Luchetti et al., 2010).

12) Studies have shown that melatonin exhibits anticancer activity both in vivo and in vitro and may improve the efficacy of typical cancer treatments when used in conjunction (Lang, 2008). Melatonin reduced chemotherapy-induced cardiotoxicity, neurotoxicity, nephrotoxicity, thrombocytopenia (reduced platelet counts), stomatitis (inflammation of mouth), and asthenia (weakness), and improved response in cancer patients (Vijayalaxmi et al., 2002; Lissoni, et al., 1987, 1992; Lissoni, 2002; Neri et al., 1998; Blask et al., 2002; Anisimov, 2002). Melatonin levels reaches peak during the night but also increase after eating, which partly explains why one may feel sleepy after a meal (Vijayalaxmi et al., 2002; Lissoni, et al., 1987, 1992; Lissoni, 2002; Neri et al., 1998; Blask et al., 2002; Anisimov, 2002). Patients with advanced cancer who suffer diminished appetite or tissue wasting have been shown to have reduced levels of melatonin. Once produced, melatonin remains in the bloodstream only for a short time, on average between 20 and 90 minutes (Vijayalaxmi et al., 2002; Lissoni, et al., 1987, 1992; Lissoni, 2002; Neri et al., 1998; Blask et al., 2002; Anisimov, 2002). This is because melatonin is highly fat soluble (lipophilic) and somewhat water soluble (hydrophilic), enabling it to easily penetrate every cellular compartment (membrane, cytoplasm, and nucleus), and enters every cell in the body. Melatonin's amphiphilicity, or ability to both absorb and repel water in conjunction with its ability to act as a weak preventive antioxidant, a weak metal ion chelator, and a direct free radical scavenger enables it to counteract oxidative stress within the chaotic tumor microenvironment (Vijayalaxmi et al., 2002; Lissoni, et al., 1987, 1992; Lissoni, 2002; Neri et al., 1998; Blask et al., 2002; Anisimov, 2002).

Melatonin can kill directly many different types of human tumor cells. It is a naturally produced cytotoxin, which can induce tumor cell death (apoptosis) (Vijayalaxmi et al., 2002; Lissoni, et al., 1987, 1992; Lissoni, 2002; Neri et al., 1998; Blask et al., 2002; Anisimov, 2002). In instances where the tumor has already been established itself in the body, melatonin has been shown to inhibit the tumor's growth rate. Melatonin exhibits natural oncostatic activity and inhibits cancer cell growth. In patients with cancer already has become a noticeable physical burden and produced overt symptoms, melatonin has been shown to alleviate numerous cancer symptoms and to inhibit the development of a new tumor blood vessels (tumor angiogenesis), which in turn inhibits the cancer from spreading further (metastasis) (Vijayalaxmi et al., 2002; Lissoni, et al., 1987, 1992; Lissoni, 2002; Neri et al., 1998; Blask et al., 2002; Anisimov, 2002). (Vijayalaxmi et al., 2002; Lissoni, et al., 1987, 1992; Lissoni, 2002; Neri et al., 1998; Blask et al., 2002; Anisimov, 2002). Melatonin can retard tumor metabolism and development by lowering the body temperature; it is a natural inducer of hypothermia. Furthermore, as an inducer of antioxidants and itself a weak preventive antioxidant, melatonin hinders tumor cells from participating in free radical damage to normal cells and consequently limits oxidative damage to DNA, lipids, amino acids, and proteins (Vijayalaxmi et al., 2002; Lissoni, et al., 1987, 1992; Lissoni, 2002; Neri et al., 1998; Blask et al., 2002; Anisimov, 2002). In the unfortunate circumstance in which cancer has already overwhelmed, the body's innate cancer-fighting capabilities, including the anti-cancer activity of naturally produced melatonin (levels of which are reduced in most cancer patients), supplemental melatonin may be beneficial (Vijayalaxmi et al., 2002; Lissoni, et al., 1987, 1992; Lissoni, 2002; Neri et al., 1998; Blask et al., 2002; Anisimov, 2002). Melatonin plays a critical role in the host defense system against cancer's progression by activating the cytokine system, which exerts growth-inhibiting properties, and by stimulating the cytotoxic activity of macrophages and monocytes (Vijayalaxmi et al., 2002; Lissoni, et al., 1987, 1992; Lissoni, 2002; Neri et al., 1998; Blask et al., 2002; Anisimov, 2002).

\section{Melatonin: Coronavirus (SARS-CoV-2)}

Severe acute respiratory syndrome coronavirus-2 (SARS$\mathrm{CoV}-2)$ is a novel coronavirus responsible for an ongoing human pandemic (COVID-19) (Wu et al., 2020a, 2020b; Zhou et al., 2020a, 2020b; Shanmugaraj et al., 2020; Malabadi et al., 2021a, 2021b). The spread of a novel coronavirus (SARSCoV-2) disease (covid-19) has challenged the capacity of healthcare systems and the public health policies of governments worldwide. During the late December of 2019, many people were diagnosed with severe pneumonia of unknown etiology and was epidemiologically linked to a local seafood market in Wuhan, Hubei Province, People's Republic of China (Wu et al., 2020a, 2020b ; Zhou et al., 2020a, 2020b; Malabadi et al., 2021a, 2021b). The human to human spreading of the coranavirus (SARS-CoV-2) occurs due to the close contact with an infected person, exposed to coughing, sneezing, respiratory droplets or aerosols and fecal to oral transmission. These aerosols can penetrate the human body (lungs) via inhalation through the nose or mouth (Shereen et al., 2020; Shin et al., 2020). The coronavirus (SARS-CoV-2) designated as COVID-19 prominently affect the respiratory tract (both lower and upper respiratory tract), with the initial symptoms of common cold, fever, dry cough, fatigue, general feeling of being unwell, runny nose, aches and pains, nasal 
congestion, loss of taste or smell, loss of speech or movement, headache, sore throat, a rash on skin, or discolouration of fingers or toes, conjunctivitis, shortness of breath, chest pain or pressure, and diarrhea to severe pneumonia, difficulty in breathing and, leading to cytokine storm, ends with the patient death (Wu et al., 2020a, 2020b; Zhou et al., 2020a, 2020b; Shin et al., 2020; Malabadi et al., 2021a, 2021b). Infection with these highly pathogenic coronaviruses (SARS-CoV-2) could result in the acute respiratory distress syndrome (ARDS) and acute lung injury (ALI) followed by the failure of the lung function and death (Wu et al., 2020a, 2020b). The pathological features of covid-19 greatly resemble those seen in SARS and Middle Eastern respiratory syndrome (MERS) coronavirus infection (Xu et al., 2020). In addition, the liver biopsy specimens of the patient with covid-19 showed moderate microvesicular steatosis and mild lobular and portal activity, indicating the injury could have been caused by either SARS-CoV-2 infection or drug-induced liver injury (Xu et al., 2020). Lymphopenia is a common feature in the patients with covid-19 and might be a critical factor associated with disease severity and mortality (Xu et al., 2020). Similar to influenza, advanced age has emerged as the leading host risk factor for developing severe COVID-19 (Xe et al., 2020). Lombo et al., (2021) reported that isolation and loneliness play a significant part in the innate immune system and inflammatory response to infection (Lombo et al., 2021). Public health and governmental authorities should consider mitigating the feeling of isolation as a preventative measure for severe illness (Lombo et al., 2021).

Melatonin is a multifunctional hormone that has emerged as an important active or adjuvant drug to be used at different coronavirus (SARS-CoV-2) disease (COVID-19) therapy stages (Gurunathan et al., 2021; Cardinali et al., 2020; Juybaria et al., 2020; Zhang et al., 2020; Fernandes et al., 2021). Melatonin, a well-known anti-inflammatory and antioxidative molecule, is protective against ALI/ARDS caused by viral and other pathogens (Zhang et al., 2020; Gurunathan et al., 2021). Its antiviral activity has been quite substantiated by several reports and analyzed in clinical trials (Cardinali et al., 2020; Juybaria et al., 2020; Zhang et al., 2020; Fernandes et al., 2021). Neuroprotection is an important topic when it comes to melatonin's action on coronavirus (SARS-CoV-2) disease (COVID-19) (Acuna-Castroviejo et al., 2020; Ali, 2020; Juybaria et al., 2020; Zhang et al., 2020; Fernandes et al., 2021; Gurunathan et al., 2021). The so called 'hormone of darkness', melatonin, due to its synthesis at night-time, has recently attracted the interest of infectious diseases specialists and epidemiologists, due to its adjuvant role in treating patients with COVID-19 (Anderson, 2021; Vlachou et al., 2021; Cardinali et al., 2020; Kleszczynski et al., 2020; Juybaria et al., 2020; Zhang et al., 2020; Fernandes et al., 2021; Acuna-Castroviejo et al., 2020; Ali, 2020). Melatonin, a methoxyindole present in all forms of life with aerobic respiration and whose primary function is apparently cytoprotection, has indirect antiviral actions as an antiinflammatory, antioxidant, and immunoregulatory agent
(Cardinali et al., 2020; Vlachou et al., 2021; Juybaria et al., 2020; Zhang et al., 2020; Anderson, 2021). Melatonin is also an effective chronobiotic agent to reverse the circadian disruption of social isolation and to control delirium in severely affected patients (Cardinali et al., 2020; Kleszczynski et al., 2020; Vlachou et al., 2021; Juybaria et al., 2020; Zhang et al., 2020; Gurunathan et al., 2021). As a cytoprotector, melatonin serves to combat several diseases such as diabetes, metabolic syndrome, and ischemic and nonischemic cardiovascular diseases, which aggravate COVID-19 disease (Cardinali et al., 2020; Juybaria et al., 2020; Zhang et al., 2020; Fernandes et al., 2021). Since melatonin is an effective means to control cognitive decay in minimal cognitive impairment, its therapeutic significance for the neurological sequels of SARS-CoV-2 infection should be considered (Cardinali et al., 2020; Vlachou et al., 2021; Anderson, 2021; Fernandes et al., 2021). Finally, exogenous melatonin can be used as an adjuvant capable of augmenting the efficacy of anti-SARS-CoV-2 vaccines (Cardinali et al., 2020; Juybaria et al., 2020; Zhang et al., 2020; Fernandes et al., 2021; Gurunathan et al., 2021).

Bats are nocturnal animals possessing high levels of melatonin, which may contribute to their high anti-viral resistance (Cardinali et al., 2020; Shneider et al., 2020; Vlachou et al., 2021; Juybaria et al., 2020; Zhang et al., 2020). Viruses induce an explosion of inflammatory cytokines and reactive oxygen species, and melatonin is the best natural antioxidant (Shneider et al., 2020; Vlachou et al., 2021; Juybaria et al., 2020; Zhang et al., 2020; Cardinali et al., 2020). The programmed cell death caused by coronaviruses, which can result in a significant lung damage, is also inhibited by melatonin (Shneider et al., 2020; Vlachou et al., 2021; Cardinali et al., 2020). Coronavirus causes inflammation in the lungs which requires inflammasome activity (Shneider et al., 2020; Cardinali et al., 2020). Melatonin blocks these inflammasomes (Shneider et al., 2020; Vlachou et al., 2021; Anderson, 2021). General immunity is impaired by anxiety and sleep deprivation. Melatonin improves sleep habits, reduces anxiety and stimulates immunity (Shneider et al., 2020; Juybaria et al., 2020; Zhang et al., 2020; Fernandes et al., 2021; Cardinali et al., 2020). Fibrosis may be the most dangerous complication after COVID-19. Melatonin is known to prevent fibrosis (Shneider et al., 2020; Vlachou et al., 2021; Fernandes et al., 2021). Mechanical ventilation may be necessary but yet imposes risks due to oxidative stress, which can be reduced by melatonin (Shneider et al., 2020; Anderson, 2021; Cardinali et al., 2020). Thus, by using the safe overthe-counter drug melatonin, it might be immediately able to prevent the development of severe disease symptoms in coronavirus patients, reduces the severity of their symptoms, and/or reduce the immuno-pathology of coronavirus infection on patients' health after the active phase of the infection is over (Shneider et al., 2020; Juybaria et al., 2020; Zhang et al., 2020; Fernandes et al., 2021). 
Melatonin be given consideration for prophylactic use or treatment alone or in combination with other drugs for controlling coronavirus (SARS-CoV-2) infections (Anderson, 2021; Reiter et al., 2020; Shneider et al., 2020; Anderson and Reiter, 2020; Juybaria et al., 2020; Zhang et al., 2020; Fernandes et al., 2021; Brusco et al., 2021). Melatonin's multiple actions as an anti-inflammatory, anti-oxidant, and anti-viral (against other viruses) make it a reasonable choice for controlling SARS-CoV-2 (Reiter et al., 2020; Anderson and Reiter, 2020; Juybaria et al., 2020; Zhang et al., 2020; Shneider et al., 2020; Anderson et al., 2015; Maestroni, 2000; Brusco et al., 2021). Melatonin is readily available, can be easily synthesized in large quantities, is inexpensive, has a very high safety profile and can be easily self-administered (Reiter et al., 2020; Juybaria et al., 2020; Zhang et al., 2020). Under the current critical conditions, large doses of melatonin alone or in combination with currently-recommended drugs, e.g., hydroxychloroquine/chloroquine, to resist COVID-19 infection would seems to be judicious (Reiter et al., 2020; Juybaria et al., 2020; Zhang et al., 2020; Shneider et al., 2020; Brusco et al., 2021). Melatonin is a molecule that negatively regulates the overreaction of the innate immune response and excess inflammation, promoting adaptive immune activity (Reiter et al., 2020; Anderson and Reiter, 2020; Juybaria et al., 2020; Zhang et al., 2020). Moreover, the indole is an endogenous molecule, produced in small amounts, whose synthesis diminishes with increased age (Reiter et al., 2020; Juybaria et al., 2020; Zhang et al., 2020; Shneider et al., 2020; Fernandes et al., 2021).

These beneficial properties of melatonin may highlight the hypothesis that melatonin may exert further clinical outcomes for COVID-19 patients (Reiter et al., 2020; Anderson and Reiter, 2020; Juybaria et al., 2020; Zhang et al., 2020 Shneider et al., 2020; Kleszczynski et al., 2020; Fernandes et al., 2021; Brusco et al., 2021). Inflammation and oxidative stress have been recognized as two principle events implicated in the Respiratory syncytial virus (RSV) pathogenesis (Juybaria et al., 2020; Zhang et al., 2020). The Respiratory syncytial virus (RSV) infection causes inflammation of the airways and epithelial cell injuries resulted in the severe breathing problems. Airway inflammation stimulates cytokine production and augmented mucous release in immunecompromised patients and children (Rudd et al., 2005). In patients with respiratory syncytial virus (RSV) infection, enormous levels of inflammatory cells infiltrate into the perivascular space of lung (Juybaria et al., 2020; Zhang et al., 2020). Therefore, experimental use of melatonin demonstrated the anti-inflammatory and antioxidant functions of melatonin against respiratory syncytial virus (RSV) infection (Juybaria et al., 2020; Zhang et al., 2020). The safety of melatonin profile has been broadly examined in different preclinical and clinical studies on wide-range doses (Juybaria et al., 2020; Zhang et al., 2020). The effective antiviral treatment for COVID-19, and the use of melatonin as an adjuvant might be worth consideration (Reiter et al., 2020; Anderson and Reiter, 2020; Juybaria et al., 2020; Zhang et al.,
2020). Although the direct protective action of melatonin against COVID-19 is unknown, its extensive applications in animal studies and human clinical trials has repeatedly verified its efficacy and safety in a broad range of disorders (Reiter et al., 2020; Anderson and Reiter, 2020; Juybaria et al., 2020; Zhang et al., 2020). Therefore, practical usage of melatonin in the current COVID-19 outbreak is suggested to be beneficial (Anderson, 2021; Reiter et al., 2020; Anderson and Reiter, 2020; Juybaria et al., 2020; Zhang et al., 2020; Vlachou et al., 2021; Brusco et al., 2021).

Viruses induces an outstanding increase in inflammatory cytokines and reactive oxygen species, and melatonin, the best natural antioxidant-anti-inflammatory-cytoprotector, has very low levels in aged patients (Cardinali et al., 2020; Tan and Hardeland, 2020; Vlachou et al., 2021). Melatonin is not viricidal but it has indirect anti-viral actions due to its antiinflammation, anti-oxidation and immune enhancing features (Zhang et al., 2020).

General immunity is impaired in severely compromised COVID-19 patients, and melatonin stimulates immunity (Cardinali et al., 2020; Tan and Hardeland, 2020; Vlachou et al., 2021). Therefore, the use of the very safe drug melatonin in adequate doses can prevent the development of severe disease symptoms in coronavirus patients. This will reduce the severity of their symptoms, and/or reduce the immunopathology of coronavirus infection on patients' health after the active phase of the infection is over (Cardinali et al., 2020; Tan and Hardeland, 2020; Brusco et al., 2021). In addition, melatonin may also help to reduce reinfections and serve as a powerful immunopotentiating adjuvant for future vaccines (Cardinali et al., 2020; Tan and Hardeland, 2020; Vlachou et al., 2021; Brusco et al., 2021). The experimental results reported by Fietosa et al., (2020) confirmed the therapeutic administration of melatonin can be effective and Mpro inhibitor to prevent viral replication by binding to viral protease (Fietosa et al., 2020). Therefore, melatonin could play an adjunct therapeutic role in treating covid-19 at different stage of the disease ( Fietosa et al., 2020; Anderson, 2021; Vlachou et al., 2021; Cardinali et al., 2020; Kleszczynski et al., 2020; Juybaria et al., 2020; Zhang et al., 2020; Fernandes et al., 2021; Acuna-Castroviejo et al., 2020; Ali, 2020). Therefore, clinical studies on the possible therapeutic value of melatonin on this infection should be performed in the near future (Feitosa et al., 2020; Gurunathan et al., 2021).

The potentiality of melatonin, a molecule of unusual phylogenetic conservation present in all known aerobic organisms, to serve as a preventive and therapeutic agent in COVID-19 pandemic has been advocated (Brusco et al., 2021). Melatonin (a) may prevent SARS-CoV-2 infection; (b) is suitable as an effective antiinflammatory/immunoregulatory/antioxidant agent; (c) counteracts chronodisruption; (d) combats several comorbidities such as diabetes, metabolic syndrome, and ischemic and non-ischemic cardiovascular diseases, which 
aggravate COVID-19 disease; (e) exerts a neuroprotective effect in acutely and chronically affected SARS-CoV-2 patients; and (f) can be an adjuvant to potentiate anti-SARSCoV-2 vaccines (Brusco et al., 2021; Anderson, 2021; Vlachou et al., 2021; Cardinali et al., 2020; Kleszczynski et al., 2020; Juybaria et al., 2020; Zhang et al., 2020; Fernandes et al., 2021; Acuna-Castroviejo et al., 2020; Ali, 2020). This multifactorial therapeutic potential is unique to melatonin and is not shared by any other therapeutic drug candidate for the COVID 19 pandemic (Brusco et al., 2021). As a chronobiotic agent, melatonin may restore the optimal circadian pattern of the sleep / wake cycle and improved clinical condition in individuals with COVID-19 pneumonia admitted to hospital (Brusco et al., 2021). A recent study endorses the efficacy and tolerability of a high dose of melatonin as an adjuvant therapy in ICU patients, in addition to standard and/or empirical therapy for COVID-19 pneumonia (Brusco et al., 2021). This study confirmed the efficacy of a relatively low dose of melatonin to reduce the hospital length of stay in pneumonia associated with COVID-19 patients (Brusco et al., 2021; Anderson, 2021; Vlachou et al., 2021; Cardinali et al., 2020; Kleszczynski et al., 2020; Juybaria et al., 2020; Zhang et al., 2020; Fernandes et al., 2021; Acuna-Castroviejo et al., 2020; Ali, 2020)

In one of the study reported by Fernandes et al., (2021), a COVID-19-signature composed of 455 genes of 288 human lungs (GTEX, UCSD) was correlated with melatonin-index by Pearson correlation test, gene-set enrichment analysis, and networking tool that integrates the connectivity between the most expressed genes, and compared the same set of genes under different states (Fernandes et al., 2021). This three independent procedures pointed to a negative relationship between melatonin-index and SARS-CoV-2 infection (Fernandes et al., 2021). The entry in epithelial AT2 cells should be hampered by a positive correlation TMRPSS 2 and a negative correlation with the coding gene for furin, suggesting dysfunctional processing in virus spike (Fernandes et al., 2021). Moreover, melatonin-index also negatively correlates with the genes that codify the proteins of multi-molecular receptor complex CD147, the gateway in macrophages, and other immune cells (Fernandes et al., 2021). Therefore, lung and respiratory tract melatonin could be a natural protective factor and opened a new epidemiological and pharmacological perspectives, as high melatonin-index scores could be predictive of asymptomatic carriers, and nasal administrated melatonin could prevent evolution of covid-19 virus (Fernandes et al., 2021; Brusco et al., 2021; Anderson, 2021; Vlachou et al., 2021; Cardinali et al., 2020; Kleszczynski et al., 2020; Juybaria et al., 2020; Zhang et al., 2020; Fernandes et al., 2021; Acuna-Castroviejo et al., 2020; Ali, 2020).

Based on clinical features, pathology, the pathogenesis of acute respiratory disorder induced by either highly homogenous coronaviruses or other pathogens, the evidence suggests that excessive inflammation, oxidation, and an exaggerated immune response very likely contribute to
COVID-19 pathology (Zhang et al., 2020). This leads to a cytokine storm and subsequent progression to acute lung injury (ALI)/acute respiratory distress syndrome (ARDS) and often death (Zhang et al., 2020). Melatonin, a well-known anti-inflammatory and anti-oxidative molecule, is protective against ALI/ARDS caused by viral and other pathogens (Zhang et al., 2020; Anderson, 2021; Vlachou et al., 2021; Cardinali et al., 2020; Kleszczynski et al., 2020; Juybaria et al., 2020; Fernandes et al., 2021; Acuna-Castroviejo et al., 2020; Ali, 2020). Melatonin is effective in critical care patients by reducing vessel permeability, anxiety, sedation use, and improving sleeping quality, which might also be beneficial for better clinical outcomes for COVID-19 patients (Zhang et al., 2020). Melatonin has a high safety profile and significant data confirmed that melatonin limits virus-related diseases which is beneficial for COVID-19 patients (Zhang et al., 2020). Additional experiments and clinical studies are required to confirm this speculation (Zhang et al., 2020). As discussed in a recent review (Cardinali et al. 2020), melatonin might counteract the consequences of COVID-19 via salutary effects on the sleep/wake cycle and more generally on chronobiology, as well as through its antioxidant and antiinflammatory effects (Anderson, 2021; Vlachou et al., 2021; Cardinali et al., 2020; Kleszczynski et al., 2020; Juybaria et al., 2020; Zhang et al., 2020; Fernandes et al., 2021; AcunaCastroviejo et al., 2020; Ali, 2020). Notably, melatonin has a high safety profile. Therefore, melatonin limits virus-related diseases and would also likely be beneficial in COVID-19 patients (Zhang et al., 2020).

\section{Influence of dietary sources of melatonin on sleep quality}

Melatonin was originally identified in 1958, as a neurohormone in the pineal gland of cattle. In the late 1970s, melatonin was identified in coffee and coffee beans are the excellent source of melatonin (Ramakrishna et al., 2012; Tan et al., 2012; Pereira et al., 2020; Peuhkuri et al., 2012). Melatonin is synthesized from tryptophan, an essential dietary amino acid (Murch et al., 2000; Murch et al., 2001; Murch and Saxena, 2002; Murch et al., 1997; Pereira et al., 2020; Peuhkuri et al., 2012). Melatonin secretion is strongly related to the duration of darkness (Murch et al., 2000; Murch et al., 2001; Murch and Saxena, 2002; Murch et al., 1997; Pereira et al., 2020; Van Tassel and O'Neill, 2001). Sleep is an essential biological phenomenon necessary for body regulation and quality of life at any age (Pereira et al., 2020; Peuhkuri et al., 2012). Melatonin is a circadian hormone produced at night by the pineal gland, with peak production around 02:00 a.m. in humans, regulated by the light/dark cycle, under the control of the suprachiasmatic nucleus (SCN) of the anterior hypothalamus in the brain (Daugaard et al., 2017; Pereira et al., 2020; Peuhkuri et al., 2012). One possible mechanism by which diet can influence circadian rhythms is by modifying the secretion of melatonin. Melatonin is a circulating neurohormone secreted predominantly at night (Pereira et al., 2020; Peuhkuri et al., 2012). Light is the most influential environmental factor (Pereira et al., 2020; Peuhkuri 
et al., 2012). In addition, melatonin synthesis depends upon availability of its precursor, tryptophan, which is an essential amino acid and is thus an essential component of the diet. If intake of tryptophan is severely restricted, synthesis of melatonin is significantly reduced in humans (Murch et al., 2000; Murch et al., 2001; Murch and Saxena, 2002; Murch et al., 1997; Pereira et al., 2020; Peuhkuri et al., 2012). Melatonin synthesis is controlled by both an endogenous circadian clock and by environmental light. Light is the dominant environmental factor that controls melatonin synthesis (Murch et al., 2000; Murch et al., 2001; Murch and Saxena, 2002; Murch et al., 1997; Pereira et al., 2020; Peuhkuri et al., 2012; Lang, 2008; Hernandez-Ruiz and Arnao, 2008a, 2008b). Pineal melatonin levels begin increasing in the late evening, reaching the maximum in the early hours between 2:00 and 4:00 a.m, followed by a slow decline to lower daytime levels (Pereira et al., 2020; Peuhkuri et al., 2012). Daytime levels of melatonin are barely detectable. In addition to sunlight, artificial indoor lighting can be bright enough to prevent the nocturnal release of melatonin (Pereira et al., 2020; Peuhkuri et al., 2012; Karasek and Winczyk, 2006). In general, melatonin production decrease with aging. Once synthesized, melatonin is not stored in producing cells, but is quickly released into the blood and begins circulation (Pereira et al., 2020; Peuhkuri et al., 2012). The metabolism of melatonin is rapid, and its halflife in humans varies between 10 and $60 \mathrm{~min}$ following exogenous administration. In addition, melatonin concentration can be measured in other body fluids as saliva and urine. It is deactivated mostly by the liver and excreted in urine (Pereira et al., 2020; Peuhkuri et al., 2012).

A cup of coffee is estimated to contain even as much as $40 \mathrm{mg}$ of melatonin (Ramakrishna et al., 2012; Akula et al., 2012; Pereira et al., 2020; Peuhkuri et al., 2012; Ursing et al., 2003). Caffeine has both the stimulatory and inhibitory mechanisms affecting the levels of melatonin. In general, diets rich in vegetables, fruits and grain products contain considerable levels of dietary melatonin (Ramakrishna et al., 2012; Pereira et al., 2020; Peuhkuri et al., 2012; Ursing et al., 2003; Murch et al., 2000; Murch et al., 2001; Murch and Saxena, 2002; Murch et al., 1997; Tan et al., 2010). Melatonin has been detected in notable amounts for example in tomatoes, olives, barley, rice and walnuts (Pereira et al., 2020; Peuhkuri et al., 2012; Murch et al., 2000; Murch et al., 2001; Murch and Saxena, 2002; Murch et al., 1997; Pereira et al., 2020; Peuhkuri et al., 2012). The consumption of food sources of melatonin is associated with health benefits, significantly increasing serum concentrations and raising the antioxidant capacity in humans, being therefore considered a nutraceutical (Pereira et al., 2020; Murch et al., 2000; Murch et al., 2001; Murch and Saxena, 2002; Murch et al., 1997; Sturtz et al., 2011; Pereira et al., 2020). The consumption of milk and sour cherries which are the sources of melatonin, may improve sleep quality in humans (Pereira et al., 2020; Castro et al., 2011; Peuhkuri et al., 2012). Therefore, food sources of melatonin acts as adjuvants in the prevention and treatment of sleep disorders (Pereira et al., 2020; Peuhkuri et al., 2012; Murch et al., 2000; Murch et al., 2001; Murch and Saxena, 2002; Murch et al., 1997; Pereira et al., 2020; Peuhkuri et al., 2012). A lack of good and quality sleep has many negative effects on health, such as metabolic dysfunction, hypertension, vascular disorders, and neurocognitive and cardiovascular diseases, suffers from sleep disorders, mainly insomnia, leading to an increase in mortality (Pereira et al., 2020; Peuhkuri et al., 2012; Bae et al., 2016; Cappuccio et al., 2010; Zimmermann et al., 1993). The endogenous levels of melatonin decrease with aging, possibly due to diminished perception of light by the retina and/or by the decline in physiological activity of the pineal gland, leading to a higher incidence of sleep disorders (Pereira et al., 2020; Peuhkuri et al., 2012). Besides circadian regulation and sleep improvement, melatonin bioactivities include antioxidant, anti-inflammatory and immune modulatory effects, memory improvement, neuroprotection, cardiovascular system modulation, bone homeostasis, lipid and glucose metabolism, and tumour inhibition (Pereira et al., 2020; Peuhkuri et al., 2012). As light is the main inhibitory environmental factor influencing melatonin production, hormone levels increase between 01:00 and 04:00 p.m. and are almost undetectable during the day (Pereira et al., 2020; Peuhkuri et al., 2012; Arnao and Hernández-Ruiz, 2006).

Among foods of animal origin, high concentrations of melatonin are found in eggs, fish, meat, animal and human milk (Karunanithi, et al., 2014; Pereira et al., 2020; Peuhkuri et al., 2012). Milk is already known to promote sleep because of its high levels of tryptophan that can be converted to melatonin (Peuhkuri et al., 2012; Karunanithi, et al., 2014; Pereira et al., 2020; Milagres et al., 2014). Fatty fish (fat content greater than 5\%) is one of the main sources of vitamin D, omega 3 (HPA, DHA) and tryptophan, play an important role in the prevention of physical and mental disorders, besides being important in the regulation of serotonin levels and sleep quality (Pereira et al., 2020; Hansen et al., 2014; Peuhkuri et al., 2012). Melatonin has also been identified in many foods of plant origin, such as nuts, fruits, seeds, cereals, oils, coffee, wine, and beer (Tan et al., 2014; Pereira et al., 2020; Peuhkuri et al., 2012; Forsyth, 2020; Murch et al., 2000; Murch et al., 2001; Murch and Saxena, 2002; Murch et al., 1997; Erland and Saxena, 2018; Erland et al., 2018a, 2018b, 2018c). Some cereals such as wheat, oats, and barley have relatively high levels of melatonin $(14.9 \mathrm{ng} / \mathrm{g}, 7.7 \mathrm{ng} / \mathrm{g}$, and $6.0 \mathrm{ng} / \mathrm{g}$, respectively) (Forsyth, 2020; Meng et al., 2017; Murch et al., 2000; Murch et al., 2001; Murch and Saxena, 2002; Murch et al., 1997; Pereira et al., 2020; Peuhkuri et al., 2012). With respect to melatonin in fruits, grapes, beer produced from barley, and their derivatives (wine and juice), cherries, strawberries and kiwis have the highest concentrations (Maldonado et al., 2009; Pereira et al., 2020; Stege et al., 2010; Peuhkuri et al., 2012; Forsyth, 2020; Murch et al., 2000; Murch et al., 2001; Murch and Saxena, 2002; Murch et al., 1997; Erland and Saxena, 2018; Erland et al., 2018a, 2018b, 2018c). Among vegetables, the main sources of 
melatonin are peppers, tomatoes, and mushrooms (Pereira et al., 2020; Peuhkuri et al., 2012; Oba et al., 2008; Lin et al., 2011; Meng et al., 2017; Murch et al., 2000; Murch et al., 2001; Murch and Saxena, 2002; Murch et al., 1997). After oral administration, melatonin is well absorbed, widely distributed and completely metabolized. It is able to pass the blood-brain barrier. The intake of food sources of melatonin significantly increased its circulating levels in humans and presented positive effects on insomnia and other human pathologies (Posadzki et al., 2018). Therefore, melatonin tablets are recommended for sleep disorders and insomnia.

\section{FUNCTION OF MELATONIN IN PLANTS}

Melatonin (N-acetyl-5-methoxy-tryptamine) is an indolic compound well known as animal hormone was first discovered and quantified mainly in mono and dicotyledon edible plant families in 1995 (Dubbels et al., 1995; Hattori et al., 1995; Van Tassel et al., 1995; Kolar et al., 1995; Erland et al., 2016; Murch et al., 2000; Murch et al., 2001; Murch and Saxena, 2002; Murch et al., 1997; Pereira et al., 2020; Peuhkuri et al., 2012). In higher plants, the first identification of endogenous melatonin was described in 1993 by van Tassel and O'Neill in a congress communication (Van Tassel and O'Neill, 1993; Van Tassel and O'Neill, 2001). The authors had detected melatonin by radioimmunoassay (RIA) and gas chromatography with mass spectrometry (GC-MS) in the Convolvulaceae ivy morning glory (Pharbitis nil L., syn. Ipomoea nil L.) and in tomato fruits (Solanum lycopersicum L.), although the results were not published extensively until 1995 (Van Tassel et al., 1995; Arnao, 2014; Arnao and Hernández-Ruiz, 2006). Further in 1995, another study simultaneously demonstrated the presence of melatonin in higher plants. Dubbels and coworkers used RIA and HPLCMS to measure the melatonin levels in extracts of Nicotiana tabacum L. and in five edible plants (Dubbels et al., 1995; Arnao and Hernández-Ruiz, 2006). In 1995, melatonin was also detected in large number of edible plants was quantified by RIA and liquid chromatography (HPLC) with fluorescence detection (Hattori et al., 1995; Arnao and Hernández-Ruiz, 2006). Another communication appeared in the same year, in which a Czech research group identified the presence of melatonin in Chenopodium rubrum L. using liquid chromatography with mass identification (LCMS/MS) (Kolar et al., 1995; Arnao, 2014; Arnao and Hernández-Ruiz, 2006). Since then, melatonin has been detected and quantified in roots, shoots, leaves, fruits and seeds of a considerable variety of plant species (Arnao and Hernández-Ruiz, 2006; Forsyth, 2020; Murch et al., 2000; Murch et al., 2001; Murch and Saxena, 2002; Murch et al., 1997; Erland and Saxena, 2018; Erland et al., 2018a, 2018b, 2018c). Melatonin is present in all plant species with large variations in its level depending on the plant organ or tissue (Arnao and Hernández-Ruiz, 2007; Arnao, 2014; Arnao and Hernández-Ruiz, 2008; Murch et al., 2000; Murch et al., 2001; Murch and Saxena, 2002; Murch et al., 1997; Pereira et al., 2020; Peuhkuri et al., 2012; Arnao and Hernández-Ruiz, 2006). It seems to be more abundant in aromatic plants and in leaves than in seeds (Arnao, 2014; Atanu et al., 2014; Arnao and Hernández-Ruiz, 2006). Melatonin is produced in both mammals and plants through the tryptophan metabolic pathway with serotonin being the immediate precursor (Okazaki and Ezura, 2009; Hardeland et al., 2006; Hardeland and Pandi-Perumal, 2005; Murch et al. 2000; Bhattacharjee and Dey, 2018; Kolar and Machackova, 2005).

The biosynthesis of melatonin has been reported in in vitro Hypericum perforatum L. plants (Forsyth, 2020; Murch et al., 2000; Murch, 2000; Murch et al., 2001; Murch and Saxena, 2002; Murch et al., 1997; Erland and Saxena, 2018; Erland et al., 2018a, 2018b, 2018c). In addition to melatonin, and its major metabolite, N1-acetyl-N2-formyl-5-methoxykynuramine (AFMK), has also been identified in an aquatic plant [Eichhornia crassipes (Mart) Solms], the water hyacinth (Tan et al., 2007). Ye et al., (2017) reported simple, rapid method for determination of melatonin in plant tissues by UPLC coupled with high resolution orbitrap mass spectrometry (Ye et al., 2017; Arnao and Hernández-Ruiz, 2006, 2007a, 2007b, 2008, 2015; Arnao, 2014; Fan et al., 2018; Hardeland, 2016; Hernandez-Ruiz et al., 2005).

Plant melatonin may play unique roles in plants as well as similar functions in animals. Furthermore, exogenously applied melatonin affects developmental processes during both vegetative and reproductive growth (Park, 2011; Caliskan et al., 2017; Murch et al., 2000; Murch et al., 2001; Murch and Saxena, 2002; Murch et al., 1997; Pereira et al., 2020; Peuhkuri et al., 2012). The decomposition of microorganisms releases melatonin into the surrounding material; as a result, the rootlets of the plants may absorb this melatonin and recycle it (Murch et al., 2000; Murch et al., 2001; Murch and Saxena, 2002; Murch et al., 1997; Pereira et al., 2020; Peuhkuri et al., 2012). Many microorganisms including bacteria and fungi produce melatonin. The effects of melatonin on vegetative growth resemble the activities of auxin, e.g., stimulation of root initiation and coleoptile elongation (Murch et al., 2000; Murch et al., 2001; Murch and Saxena, 2002; Murch et al., 1997; Pereira et al., 2020; Peuhkuri et al., 2012). These effects of melatonin may appear indirectly by influencing the auxin levels (Park, 2011; Caliskan et al., 2017; Arnao and Hernández-Ruiz, 2006, 2007a, 2007b, 2008, 2015; Arnao, 2014; Fan et al., 2018; Hardeland, 2016; Hernandez-Ruiz et al., 2005). During reproductive development, melatonin may act as a transition signal to indicate the time point for seed growth (Park, 2011). Considering the ubiquitous distribution of melatonin in angiosperms, melatonin may play other important roles in plants (Park, 2011; Caliskan et al., 2017; Arnao and Hernández-Ruiz, 2006; Forsyth, 2020; Murch et al., 2000; Murch et al., 2001; Murch and Saxena, 2002; Murch et al., 1997; Erland and Saxena, 2018; Erland et al., 2018a, 2018b, 2018c). 
Edible plant tissues contain melatonin and their consumption increases the circulating melatonin supply in mammals (Murch et al., 1997; Park, 2011; Caliskan et al., 2017; Arnao and Hernández-Ruiz, 2006, 2007a, 2007b, 2008, 2015; Arnao, 2014; Fan et al., 2018; Hardeland, 2016; Hernandez-Ruiz et al., 2005). As in animals, the pathway of melatonin synthesis in plants utilizes tryptophan as an essential precursor molecule (Arnao and Hernández-Ruiz, 2006; Forsyth, 2020; Murch et al., 2000; Murch et al., 2001; Murch and Saxena, 2002; Murch et al., 1997; Erland and Saxena, 2018; Erland et al., 2018a, 2018b, 2018c). Melatonin synthesis is inducible in plants when they are exposed to abiotic stresses (extremes of temperature, toxins, increased soil salinity, drought, etc.) as well as to biotic stresses (fungal infection). Melatonin aids plants in terms of root growth, leaf morphology, chlorophyll preservation and fruit development. Commercial preparations of feverfew (Tanacetum parthenium), St John's Wort (Hypericum perforatum), and Huang-qin (Scutellaria biacalensis) leaves were recommended as a medicine for the treatment for ailments of the nervous system based on anecdotal and historical evidence (Arnao and HernándezRuiz, 2006; Forsyth, 2020; Murch et al., 2000; Murch et al., 2001; Murch and Saxena, 2002; Murch et al., 1997; Erland and Saxena, 2018; Erland et al., 2018a, 2018b, 2018c). Feverfew preparations, taken prophylactically, can reduce the frequency and severity of migraine attacks in some patients (Murch et al., 1997). The efficacy of feverfew has been attributed to a sesquiterpene lactone, parthenolide. Melatonin was found in relatively high concentrations in two of the other medicinal plants, St John's Wort and Huang-qin (Murch et al., 1997). The amount of melatonin found in feverfew, St John's Wort, and Huang-qin was higher than previously found in edible-plant products (Forsyth, 2020; Murch et al., 2000; Murch et al., 2001; Murch and Saxena, 2002a; Murch et al., 1997; Erland and Saxena, 2018; Erland et al., 2018a, 2018b, 2018c; Murch and Saxena, 2002b). In terms of nutrition, melatonin is interesting both as a natural constituent of food, and as a food additive (Hardeland and Pandi-Perumal. 2005; Arnao and Hernández-Ruiz, 2006; Forsyth, 2020; Murch et al., 2000; Murch et al., 2001; Murch and Saxena, 2002; Murch et al., 1997; Erland and Saxena, 2018; Erland et al., 2018a, 2018b, 2018c).

Melatonin consumed in medicinal plants, nuts and vegetables is absorbed through the human digestion system and metabolites of plant-based melatonin have been found in urine samples (Murch et al., 2000; Murch et al., 2001; Murch and Saxena, 2002; Murch et al., 1997; Ansari et al., 2010). The levels of melatonin in plants are highly variable from species to species. The reported concentration ranges are from several $\mathrm{pg} / \mathrm{g}$ tissue to multiple $\mu \mathrm{g} / \mathrm{g}$ tissue (Arnao and HernándezRuiz, 2006; Forsyth, 2020; Murch et al., 2000; Murch et al., 2001; Murch and Saxena, 2002; Murch et al., 1997; Erland and Saxena, 2018; Erland et al., 2018a, 2018b, 2018c). Datura metel is a plant that contains several different neurologically active phytochemicals which affect human health (Murch et al., 2009). In one of the study reported, melatonin and serotonin were found at the highest levels in the least developed flower buds with decreasing concentrations as the flower buds matured (Murch et al., 2009). Cold stress significantly increased the concentration of melatonin in young flower buds. In the developing fruit, melatonin was present at relatively stable, high concentrations for the first 10 days after anthesis (Murch et al., 2009). After 10-15 days, the ovule had grown to a sufficient size for excision and analysis and melatonin was found to be at the highest concentrations in the developing ovule with minimal concentrations of the neuroindoles in the fleshy fruit (Murch et al., 2009). Together, these data indicate that melatonin may play a role in protecting the reproductive tissues during flower and seed formation in a Datura species (Murch et al., 2009; Forsyth, 2020; Murch et al., 2000; Murch, 2000; Murch et al., 2001; Murch and Saxena, 2002; Murch et al., 1997; Erland and Saxena, 2018; Erland et al., 2018a, 2018b, 2018c).

Melatonin acts as a circadian regulator, cytoprotector and growth promotor. Melatonin also enhances the rate of germination and growth and plant productivity. It acts as a retardant in stress-induced leaf senescence (Forsyth, 2020; Murch et al., 2000; Murch, 2000; Murch et al., 2001; Murch and Saxena, 2002; Murch et al., 1997; Erland and Saxena, 2018; Erland et al., 2018a, 2018b, 2018c). The physiological function in plants, melatonin shows auxin activity and is an excellent antioxidant, regulating the growth of roots, shoots, and explants, activating seed germination and rhizogenesis (lateral and adventitious-roots), and delaying induced leaf senescence (Arnao, 2014; Arnao and Hernández-Ruiz, 2006). Its ability to strengthen plants subjected to abiotic stress such as drought, cold, heat, salinity, chemical pollutants, herbicides, and UV radiation makes melatonin an interesting candidate for use as a natural biostimulating substance for treating field crops (Arnao, 2014; Arnao and Hernández-Ruiz, 2006; Forsyth, 2020; Murch et al., 2000; Murch et al., 2001; Murch and Saxena, 2002a; Murch et al., 1997; Erland and Saxena, 2018; Erland et al., 2018a, 2018b, 2018c).

The use of plants rich in melatonin as a tool in phytoremediation techniques for the recovery of contaminated soils such as mining operations, industrial waste, or soils containing high levels of phytochemicals due to agricultural use (Arnao, 2014; Arnao and Hernández-Ruiz, 2006).

Melatonin occurs with dietary supplements, increasing blood melatonin levels through eating natural foods such as plants could be considered a healthy habit (Arnao, 2014; Arnao and Hernández-Ruiz, 2006; Aher and Wahi, 2011). An oral dose of melatonin of up to 1 gram per day produces no adverse effects in humans. In addition, melatonin is easily absorbed via the gastrointestinal tract (Arnao, 2014; Arnao and Hernández-Ruiz, 2006). Hence melatonin is used as a nutraceutical product through the intake of melatonin-rich plants as a healthy phytochemical (Akula et al., 2012; Arnao, 2014; Arnao and Hernández-Ruiz, 2006). Therefore, plants with high levels of endogenous melatonin that could be used as a natural source of nutraceuticals (Arnao, 2014; Arnao and 
Hernández-Ruiz, 2006; Forsyth, 2020; Murch et al., 2000; Murch et al., 2001; Murch and Saxena, 2002a; Murch et al., 1997; Erland and Saxena, 2018; Erland et al., 2018a, 2018b, 2018c).

Melatonin is an indoleamine neurohormone (biogenic indoleamine) structurally related with tryptophan, serotonin, indole-3-acetic acid (IAA) (Reiter and Tan, 2002 ;Arnao and Hernández-Ruiz, 2006; Erland et al., 2015, 2016; Gong et al., 2017; Mukherjee, 2018). Melatonin has been identified in numerous plants, many of which are human foods, such as olive oil, walnuts, pineapples, tomatoes, ginger, and others (Lang, 2008; Badria 2002; Reiter and Tan 2002; Reiter et al. 2005; Arnao and Hernández-Ruiz, 2006). Dietary melatonin has been shown to increase melatonin levels and total antioxidant status of human serum (Lang, 2008; Arnao and Hernández-Ruiz, 2006). Melatonin was detected in different parts of plants such as leaves, stems, roots, fruits, seeds which is involved in the growth, reproduction, development, stress and acts as a growth hormone (Khan et al., 2019; Gong et al., 2017; Cui et al., 2017; Hernández-Ruiz and Arnao, 2008; Arnao and Hernández-Ruiz, 2006; Boccalandro et al., 2011; Byeon et al., 2012; Erland et al., 2015, 2016; Reiter et al., 2015; Hardeland, 2016; Chen et al., 2019; Erland and Saxena, 2018; Erland et al., 2018a, 2018b, 2018c; Kolar et al., 2002; Korkmaz et al., 2017a, 2017b). Melatonin is a potent antioxidant and has many roles in plant growth including root induction and stress mitigation as well as regulating circadian rhythms in mammals and potentially in plants (Forsyth, 2020; Murch et al., 2000; Murch et al., 2001; Murch and Saxena, 2002a; Murch et al., 1997; Erland and Saxena, 2018; Erland et al., 2018a, 2018b, 2018c). The medicinal phytochemistry of melatonin in plants has a common biosynthetic pathways shared by the auxin, indole-3-acetic, melatonin, and suggested a possible coordinated regulation in plants (Arnao and Hernández-Ruiz, 2006; Erland et al., 2015, 2016; Reiter et al., 2015; Hardeland, 2016; Lazar et al., 2013). The detection of melatonin in plants has different physiological role and involved in many plant growth processes (Lee and Back, 2018; Li et al., 2015; Li et al., 2020; Murch et al., 2000; Murch et al., 2001; Murch and Saxena, 2002a; Murch et al., 1997; Murch and Saxena, 2006)). Plants naturally produce melatonin a compound, that is light sensitive and regulates the circadian rhythm in humans but has many additional roles in plant growth (Forsyth, 2020; Boccalandro et al., 2011; Chen et al., 2019; Erland and Saxena, 2018; Erland et al., 2018a, 2018b, 2018c).

Herbs may be an excellent natural source of pharmacological levels of melatonin. While melatonin has antioxidant capacity at both physiological and pharmacological levels, pharmacological levels may be more efficacious for the treatment of disease (Lang, 2008; Arnao and Hernández-Ruiz, 2006). Thus, a role in photoperiodic regulation has been demonstrated because of the duration and timing of the melatonin signal (Arnao and Hernández-Ruiz, 2006; Boccalandro et al., 2011; Byeon et al., 2012; Erland and
Saxena, 2018; Erland et al., 2018a, 2018b, 2018c; Li et al., 2020). Light is used by plants for photosynthesis and as a signal of their environment. Melatonin is one of the indoleamine class of plant growth regulators (Forsyth, 2020; Murch et al., 2000; Murch et al., 2001; Murch and Saxena, 2002a; Murch et al., 1997; Erland and Saxena, 2018; Erland et al., 2018a, 2018b, 2018c). In one of the study reported by van Tassel and colleagues (2001), the possible variations in melatonin concentrations in two physiological models, Pharbitis nil Choisy seedlings under light/dark photoperiod and tomatoes (Lycopersicum esculentum Mill.) in different ripening stages (Van Tassel et al., 2001). However, there was no significant changes in the levels of melatonin was observed with respect to light/photoperiod. In the case of tomatoes, mature red fruits presented a slightly higher level of melatonin (Van Tassel et al., 2001; Arnao and Hernández-Ruiz, 2006).

The most common techniques used to measure melatonin are the radioimmunoassay and high performance liquid chromatography with electrochemical or fluorescence detection (Lee and Back, 2018; Li et al., 2015; Li et al., 2020; Arnao and Hernández-Ruiz, 2006). Lastly, high performance liquid chromatography coupled to mass- spectrometry identification is a powerful tool for the precise determination of melatonin in plant samples (Lee and Back, 2018; Li et al., 2015; Li et al., 2020; Forsyth, 2020; Murch et al., 2000; Murch, 2000; Murch et al., 2001; Murch and Saxena, 2002; Murch et al., 1997; Erland and Saxena, 2018; Erland et al., 2018a, 2018b, 2018c). The studies of melatonin in plants have concentrated on measuring its levels and its possible implications in human food, since melatonin from plant foods is absorbed from the gastrointestinal tract and incorporated in the blood stream; it also crosses the blood-brain barrier and the placenta, while at subcellular level, it is mainly incorporated in the nucleus and mitochondria (Pérez-Llamas et al., 2020; Arnao and Hernández-Ruiz, 2006; Aher and Wahi, 2011). These studies have concluded that melatonin is considered as a health-related phytochemical (Murch et al., 2000; Murch et al., 2001; Murch and Saxena, 2002a; Murch et al., 1997; Arnao and Hernández-Ruiz, 2006; Balzer and Hardeland, 1996; Van Tassel et al., 2001; Reiter et al., 2001, 2005; Benot et al., 1999).

Generally, seeds and leaves presented the highest level of melatonin and fruits the lowest (Pérez-Llamas et al., 2020; Arnao and Hernández-Ruiz, 2006; Harumi and Matsushima, 2000; Yang et al., 2002; Burkhardt et al., 2001; Manchester et al., 2000). The levels of melatonin in plant organs vary considerably, from picograms to micrograms per gram of plant material (Murch et al., 2000; Murch et al., 2001; Murch and Saxena, 2002a; Murch et al., 1997; Erland and Saxena, 2018; Erland et al., 2018a, 2018b, 2018c). Another interesting discovery is that melatonin is highly concentrated in some of the medicinal plants in the order of $\mathrm{g} / \mathrm{g}$ dry wt as in the case of Hypericum perforatum (St. John's wort), Tanacetum parthenium (feverfew) and some Chinese medicinal herbs (Murch et al., 2000; Murch et al., 2001; Murch and Saxena, 
2002a; Murch et al., 1997; Chen et al., 2003; Murch et al., 2004; Simopoulos et al., 2005; Arnao and Hernández-Ruiz, 2006). Melatonin is traditionally used as a sleep modulator in human sleeping disorders, as an anti-depressant or to combat jet-lag (Murch et al., 2000; Murch et al., 2001; Murch and Saxena, 2002a; Murch et al., 1997; Arnao and HernándezRuiz, 2006; Chen et al., 2003; Murch et al., 2004; Simopoulos et al., 2005).

Melatonin is a well-documented light sensitive molecule, as it is the regulator of circadian rhythm and light has been found to stimulate melatonin biosynthesis (Byeon et al., 2012; Forsyth, 2020; Tettamanti et al., 2000). However, the levels of light that increase melatonin biosynthesis in plants seems to be species specific (Forsyth, 2020; Posmyk et al., 2008; Posmyk et al., 2009; Sliwiak et al., 2016; Sanchez-Barcelo et al., 2016; Sarrou et al., 2015).

In 1997, Kolar and colleagues confirmed the presence of melatonin in cultivated 15 day-old plants of Chenopodium rubrum L. using liquid chromatography/tandem mass spectrometry and radioimmunoassays (Kolar et al., 1997; Arnao and Hernández-Ruiz, 2017). This experimental study also observed the possible changes in the melatonin levels in light/dark cycles of 12 hours. An oscillating behaviour was observed, showing low or undetectable melatonin levels during the light period and a considerable increase in darkness, when a maximum concentration of $240-550 \mathrm{pg} / \mathrm{g}$ fresh weight was observed (Kolar et al., 1997; Arnao and Hernández-Ruiz, 2017). This increase during darkness and the range of melatonin concentrations, similar to those observed in animals was confirmed (Kolar et al., 1997; Arnao and Hernández-Ruiz, 2017). In another experiment, different photoperiodic profiles $(6,12$ and $18 \mathrm{~h}$ of darkness), were also studied but no changes in the duration of the melatonin increase with the photoperiod applied was observed. The maximum levels of melatonin always occurred during dark conditions. Therefore, this study concluded that melatonin synthesis is not directly light-regulated but shows a circadian rhythm, as in animals (Kolar et al., 1997; Wolf et al., 2001; Arnao and Hernández-Ruiz, 2017).

In another development, the effect of the exogenous application of melatonin on the flowering of the short-day plant Chenopodium rubrum was also studied (Kolar et al., 2003; Arnao and Hernández-Ruiz, 2017). This study also confirmed that only exogenous melatonin at 100 and $500 \mu \mathrm{M}$ (much above physiological levels) had a weak inhibitory effect on flowering, but not on the timing and rhythm (phase, period) of the process (Kolar et al., 2003; Arnao and Hernández-Ruiz, 2017).

Further melatonin physiological activities were specific to melatonin molecule and not due to the similarity in structure to IAA (Forsyth, 2020; Arnao and Hernández-Ruiz, 2017; Erland et al., 2018a, 2015; Kim et al., 2016). There are also evidences that exposure to UV-B light led to an increase in melatonin levels in Amaranthus tricolor L. (Adhikary et al.,
2020; Zhang et al., 2019; Wen et al., 2016; Zhang et al., 2015; Zhao et al., 2013; Zhang et al., 2016; Zhang et al., 2017). Melatonin has many physiological activities since it acts as a potent antioxidant, mediate plant growth and development from germination, throughout morphogenesis, mediating diverse abiotic stresses including temperature, heavy metal and salinity stress (Murch et al., 2000; Murch et al., 2001; Murch and Saxena, 2002a; Murch et al., 1997; Chen et al., 2003; Murch et al., 2004; Simopoulos et al., 2005; Arnao and Hernández-Ruiz, 2006; Wolf et al., 2001; Zhang et al., 2014; Wei et al., 2018; Weeda et al., 2014; Tiryaki and Keles, 2012; Perez-Llorca et al., 2019; Pelagio-Flores et al., 2012; Nicasio et al., 2005).

Melatonin has been found to regulate IAA concentration through regulation of enzymes, cofactors, and transporters but studies have yet to find a consistent trend as the dose and species play a role in whether auxin levels are up- or downregulated by melatonin (Forsyth, 2020; Murch et al., 2000; Murch et al., 2001; Murch and Saxena, 2002a; Murch et al., 1997; Chen et al., 2003; Murch et al., 2004; Simopoulos et al., 2005; Arnao and Hernández-Ruiz, 2006; Wolf et al., 2001; Zhang et al., 2014; Wei et al., 2018; Weeda et al., 2014; Tiryaki and Keles, 2012; Perez-Llorca et al., 2019; PelagioFlores et al., 2012; Nicasio et al., 2005). Plant responses to melatonin are concentration-dependent and typically change from positive to inhibitory with increase of concentration (Forsyth, 2020; Erland et al., 2017). Melatonin effects have been found to mimic those of auxins (Forsyth, 2020; Murch et al., 2001). In one of the study it was reported that 3 months of red light exposure led to increased melatonin levels in Glycyrrhiza uralensis (licorice) plants than those grown under blue or white light (Afreen et al., 2006). A similar effect was found in Scutellaria racemosa where short time exposure to blue light initially led to increased melatonin levels but long term red exposure resulted in increased endogenous melatonin concentrations (Forsyth et al., 2020). Overall, there is a strong relationship between light and melatonin whose mechanism has yet to be described thoroughly (Forsyth, 2020; Murch et al., 2000; Murch, 2000; Murch et al., 2001; Murch and Saxena, 2002; Murch et al., 1997; Erland and Saxena, 2018; Erland et al., 2018a, 2018b, 2018c).

An interesting effect of melatonin as a protector of coldinduced apoptosis in carrot suspension cells has recently been suggested (Lei et al., 2004; Arnao and Hernández-Ruiz, 2006). In general, the application of hormones that stimulate plant development (auxins, cytokinins and gibberellins) increases the content of polyamines in plant tissues, while inhibitory hormones (abscisic acid and ethylene) decrease their content, which suggests a possible physiological activity for melatonin (Pérez-Llamas et al., 2020; Arnao and Hernández-Ruiz, 2006). Phytomelatonin is the term used for melatonin of plant origin (Pérez-Llamas et al., 2020). In general, aromatic and medicinal plants seem to have the highest phytomelatonin contents (Pérez-Llamas et al., 2020). Many physiological studies have been looked at the role of 
phytomelatonin in plants, where it has been found act as a protective molecule against physical, chemical, or biological stressors (Pérez-Llamas et al., 2020).

Plant growth has been manipulated with light affecting the levels of melatonin (Murch et al., 2000). Light has also been found to regulate the phytochemical profile of plants, including the concentrations of the indoleamines (Forsyth, 2020; Murch et al., 2000; Murch et al., 2001; Murch and Saxena, 2002a; Murch et al., 1997; Erland and Saxena, 2018; Erland et al., 2018a, 2018b, 2018c). Melatonin has been found mediating diverse aspects of plant growth and metabolism. Therefore, melatonin enables fine control of plant growth processes (Posmyk and Janas, 2009; Forsyth, 2020; Murch et al., 2000; Murch et al., 2001; Murch and Saxena, 2002a; Murch et al., 1997; Erland and Saxena, 2018; Erland et al., 2018a, 2018b, 2018c).

In one of the study, relation between the different melatonin content of two cultivars of Nicotiana tabacum and its susceptibility to ozone has been suggested (Dubbels et al., 1995; Hattori et al., 1995). Manchester et al., (2000) analyzed 15 seeds of edible plants, proposed a germ tissue protection role for melatonin (Manchester et al., 2000). A role as antioxidant against the oxidation of lipid vesicles of Gonyaulax polyedra cysts during photoperiodically induced encystment has also been proposed (Fuhrberg et al., 1995, 1997). On the other hand, the possible protective role of melatonin during flower development of Hypericum perforatum $\mathrm{L}$ has been reported. This study concluded that melatonin could act as a stress-protecting agent, providing an adaptative mechanism to ensure reproduction (Forsyth, 2020; Murch et al., 2000; Murch et al., 2001; Murch and Saxena, 2002a; Murch et al., 1997; Erland and Saxena, 2018; Erland et al., 2018a, 2018b, 2018c).

The melatonin chemical structure (indole derivative) and biosynthetic pathway (from tryptophan) suggested that melatonin might be related with IAA, as some authors have previously suggested (Forsyth, 2020; Murch et al., 2000; Murch et al., 2001; Murch and Saxena, 2002a; Murch et al., 1997; Erland and Saxena, 2018; Erland et al., 2018a, 2018b, 2018c). IAA is an auxin involved in many physiological actions, but one of the most typical is its role as growth promotor (Kolar et al., 1997; Wolf et al., 2001; Arnao and Hernández-Ruiz, 2017). This study confirmed that melatonin and IAA coexist in the tissues, and that a similar concentration gradient existed for both indoles (Murch et al., 2000; Murch et al., 2001; Murch and Saxena, 2002a; Murch et al., 1997). In another study, it was investigated the possible growthpromoting activity of melatonin in some monocots. The data obtained in Triticum aestivum L., Avena sativa L., Hordeum vulgare L. and Phalaris canariensis L. confirmed the growthpromoting action of melatonin in coleoptile longitudinalgrowth assays (Hernandez-Ruiz et al., 2005; Hernandez-Ruiz and Arnao, 2008).
Melatonin could be used to improve the phytoremediative efficiency of plants against different pollutants. Since melatonin is safe to animals and humans as well as being inexpensive, it may be a feasible and cost-effective approach to clean environmental contaminations (Tan et al., 2007).

The process of excising, explanting and culturing plant tissues imposes a substantial physiological stress on plant cells and accumulation of reactive oxygen species (ROS) (Steward et al., 1967; Forsyth, 2020). The endogenous melatonin levels recovered from explanting stress faster in plantlets cultured under blue lights (Forsyth, 2020; Murch et al., 2000; Murch et al., 2001; Murch and Saxena, 2002a; Murch et al., 1997; Erland and Saxena, 2018; Erland et al., 2018a, 2018b, 2018c). Explanting stress has also been shown to serve as an inductive signal in plants, triggering downstream signaling cascades and eventually leading to morphogenesis (Steward et al., 1967; Forsyth, 2020). Melatonin is a well-established and potent antioxidant, and previous studies have hypothesized melatonin is an important mechanism to reduce metabolic stress during regeneration (Forsyth, 2020; Murch et al., 2000; Murch et al., 2001; Murch and Saxena, 2002a; Murch et al., 1997; Erland and Saxena, 2018; Erland et al., 2018a, 2018b, 2018c).

The antioxidant potential and anthocyanin content has been increased by blue light with melatonin through multiple mechanisms (Forsyth, 2020; Brazaityte et al., 2015; DługoszGrochowska et al., 2017; Stutte, 2015; Zhang et al., 2018; Zoratti et al., 2014). This clearly indicated that melatonin with blue light has increased anthocyanin and flavonoid content, which are connected with each other (Zhang et al., 2016; Khan et al., 2019). These results suggested that melatonin may be an early inductive signal, enhanced through blue light exposure (Forsyth, 2020; Murch et al., 2000; Murch et al., 2001; Murch and Saxena, 2002a; Murch et al., 1997; Erland and Saxena, 2018; Erland et al., 2018a, 2018b, 2018c). Therefore, this study concluded that the regulation of melatonin stress response through blue light photoreceptors (Forsyth, 2020; Murch et al., 2000; Murch et al., 2001; Murch and Saxena, 2002a, 2002b; Murch et al., 1997; Erland and Saxena, 2018; Erland et al., 2018a, 2018b, 2018c). Therefore, melatonin is related to the light environment and has significant roles in light-dependent processes (Forsyth, 2020; Murch et al., 2000; Murch et al., 2001; Murch and Saxena, 2002a; Murch et al., 1997; Erland and Saxena, 2018; Erland et al., 2018a, 2018b, 2018c; Shukla et al., 2021). Furthermore, melatonin is a crucial component of plant growth regulation and it maintains a close relationship with other plant growth regulators such as abscisic acid and karrikins (Forsyth, 2020; Murch et al., 2000; Murch et al., 2001; Murch and Saxena, 2002a; Murch et al., 1997; Erland and Saxena, 2018; Erland et al., 2018a, 2018b, 2018c).

Melatonin is detected in various medicinal and food plants, and its concentration is widely variable (Salehi et al., 2019; Shukla et al., 2021). Plant generative organs (e.g., flowers, fruits), and especially seeds, have been proposed as having the highest melatonin concentrations, markedly higher than those 
found in vertebrate tissues (Salehi et al., 2019; Reiter and Tan, 2002; Shukla et al., 2021). In addition, seeds are also rich in other substances (lipids, sugars, and proteins), constituting the energetic reserve for a potentially growing seedling and beneficial for the human diet (Salehi et al., 2019). Therefore, dietary melatonin is absorbed in the gastrointestinal tract and transported into the bloodstream, the ingestion of medicinal and plant foods by mammals as a source of melatonin may be conceived as a key step in serum melatonin modulation and, consequently, health promotion (Salehi et al., 2019). Hence, the use of dietary melatonin may be extremely beneficial in helping to maximize the health-promoting effects of medicinal plants and healthy foods in humans, possibly acting in synergy with other bioactive phytochemicals (i.e., polyphenols) that are ingested daily (Salehi et al., 2019).

Melatonin was detected consistently in plants grown under blue light in all the species of Scutellaria (Forsyth, 2020; Salehi et al., 2019; Murch et al., 2000; Murch et al., 2001; Murch and Saxena, 2002a; Murch et al., 1997; Erland and Saxena, 2018; Erland et al., 2018a, 2018b, 2018c). In Scutellaria galericulata, significant quantities of abscisic acid were detected in plants grown under white light but not detected in plants grown under other light spectra (Forsyth, 2020; Murch et al., 2000; Murch et al., 2001; Murch and Saxena, 2002a, 2002b; Murch et al., 1997; Erland and Saxena, 2018; Erland et al., 2018a, 2018b, 2018c). In Scutellaria racemosa blue light exposure resulted in earlier detection of melatonin and higher levels than red light treatment, while white and green light exposure increased levels of stress phytohormones (Forsyth, 2020; Murch et al., 2000; Murch et al., 2001; Murch and Saxena, 2002a, 2002b; Murch et al., 1997; Erland and Saxena, 2018; Erland et al., 2018a, 2018b, 2018c).

In Arabidopsis thaliana CYP707A mutants, melatonin decreased germination, root length and secondary root production, red light exposure increased root length and blue light decreased secondary root production (Forsyth, 2020; Murch et al., 2000; Murch et al., 2001; Murch and Saxena, 2002a, 2002b; Murch et al., 1997; Erland and Saxena, 2018; Erland et al., 2018a, 2018b, 2018c). In case of Arabidopsis thaliana karrikin mutants revealed that melatonin decreased germination rate in Ler ecotypes and was synergistic with KAR2 to promote secondary root production in both Ler and Col ecotypes (Forsyth, 2020; Murch et al., 2000; Murch et al., 2001; Murch and Saxena, 2002a, 2002b; Murch et al., 1997; Erland and Saxena, 2018; Erland et al., 2018a, 2018b, 2018c). These experimental data indicated that the relative amounts of melatonin and serotonin are responsive to light spectra and redirect metabolic resources to enable plant adaptations to changing environments (Forsyth, 2020; Murch et al., 2000; Murch et al., 2001; Murch and Saxena, 2002a; Murch et al., 1997; Erland and Saxena, 2018; Erland et al., 2018a, 2018b, 2018c). Another study confirmed that using an in vitro cultured explants of Hypericum perforatum, where an increase in the melatonin concentration of the culture medium was correlated with a high de novo root formation in explants (Murch et al., 2001). A possible role for serotonin and melatonin as regulators of plant growth and morphogenesis was postulated (Forsyth, 2020; Murch et al., 2000; Murch et al., 2001; Murch and Saxena, 2002a; Murch et al., 1997; Erland and Saxena, 2018; Erland et al., 2018a, 2018b, 2018c). Stressed melatonin-treated plants of turf grass, bermuda grass (Cynodon dactylon) showed a lower Reactive Oxygen Species (ROS) burst, electrolyte leakage, and cell damage and higher plant height/weight, high levels of amino acids, organic acids, sugars, sugar alcohols than untreated plants, clearly affecting the carbohydrate and nitrogen metabolism, mainly solutes involved in the osmotic-stress response (Shi et al., 2015; Arnao and Hernández-Ruiz, 2015).

Advances have been made in understanding the role of melatonin in cultured cells. The study with Hypericum perforatum (St. John's wort) and with Echinacea purpurea (purple coneflower) where it was postulated as a potential plant regulator, independent of IAA, in organogenic processes (rhizo- and caulogenesis) (Forsyth, 2020; Murch et al., 2000; Murch et al., 2001; Murch and Saxena, 2002a; Murch et al., 1997; Erland and Saxena, 2018; Erland et al., 2018a, 2018b, 2018c). The study of in vitro shoots of Vaccinium corymbosum (highbush blueberry), where the morphogenic potential of melatonin was compared with that of IAA and IBA (Forsyth, 2020; Murch et al., 2000; Murch et al., 2001; Murch and Saxena, 2002a; Murch et al., 1997; Erland and Saxena, 2018; Erland et al., 2018a, 2018b, 2018c). There is great interest that melatonin might have as a dual agent, as cell protector (antioxidant activity), and as plant morphogenic regulator, under in vitro applications (Forsyth, 2020; Murch et al., 2000; Murch et al., 2001; Murch and Saxena, 2002a, 2002b; Murch et al., 1997; Erland and Saxena, 2018; Erland et al., 2018a, 2018b, 2018c; Salehi et al., 2019).

Experimental study reported by $\mathrm{Li}$ et al., (2020) demonstrated that melatonin represses seed oil and anthocyanin accumulation during seed maturation by inhibiting the expression of important genes involved in oil and anthocyanin biosynthesis, respectively ( $\mathrm{Li}$ et al., 2020). In case of Arabidopsis seeds, two essential melatonin biosynthetic genes serotonin $\mathrm{N}$-acetyltransferase1(SNAT1) and caffeic acid O-methyltransferase (COMT), independent of melatonin, have distinct functions on different metabolites, including oil, flavonoids inclusive of anthocyanins and mucilage, which might be due to their differential distribution among subcellular fractions ( $\mathrm{Li}$ et al., 2020). These results indicated that manipulation of this coregulation network is feasible by blocking melatonin biosynthesis through knocking out SNAT1 and/or COMT. Therefore, the genes serotonin Nacetyltransferase1(SNAT1) and caffeic acid Omethyltransferase (COMT) are noteworthy genetic resources for genetic modification of oil producing crops and plants to synergistically improve both oil and flavonoids in seeds (Li et al., 2020). Arabidopsis thaliana treated with melatonin and grown at $4^{\circ} \mathrm{C}$, melatonin- treated plants had significantly 
greater fresh weight, primary root length, and shoot height compared with untreated plants, the effect being both time and concentration dependent (Bajwa et al., 2014; Arnao and Hernández-Ruiz, 2015). The protective role of exogenous melatonin was also observed in mung bean (Vigna radiata) meristem cells after chilling (Szafranska et al., 2013; Arnao and Hernández-Ruiz, 2015). Treating Arabidopsis thaliana with melatonin upregulated the expression of some coldsignaling genes: the C-repeat-binding factors ( $\mathrm{CBFs})$, which control the expression of $\sim 100$ genes, providing freezing tolerance to the plants Thus, these data point to a role for melatonin in the upregulation of specific cold-responsive genes, supporting the hypothesis that melatonin plays a protective role against abiotic stresses (Shi and Chan, 2014; Arnao and Hernández-Ruiz, 2015; Bajwa et al., 2014).

The role of melatonin as a regulator of light-dark cycles has been clearly established in mammals (Reiter and Tan, 2002 ;Arnao and Hernández-Ruiz, 2015; Forsyth, 2020; Murch et al., 2000; Murch et al., 2001; Murch and Saxena, 2002a, 2002b; Murch et al., 1997; Erland and Saxena, 2018; Erland et al., 2018a, 2018b, 2018c). In plants, the circadian oscillator is able to adjust the phase of a variety of biological processes, such as gene and metabolic regulation, protein stability, among others, to coincide with daily and/or seasonal cycles (Reiter and Tan, 2002 ;Arnao and Hernández-Ruiz, 2015). Thus, circadian regulation increases photosynthesis and growth rates and may affect flowering and seed yield in crops and biotic/abiotic stress responses. This role as chronoregulator was the starting point for research into melatonin in plants and, more specifically, its possible involvement as a regulatory molecule in circadian rhythms and in aspects connected with photoperiodicity (Kolar et al., 1995; Erland et al., 2016; Arnao and Hernández-Ruiz, 2015; Forsyth, 2020; Murch et al., 2000; Murch et al., 2001; Murch and Saxena, 2002a; Murch et al., 1997; Erland and Saxena, 2018; Erland et al., 2018a, 2018b, 2018c).

In 1997, Kolar et al., (1997) demonstrated the presence of melatonin in cultivated 15- day-old Chenopodium rubrum plants and observed an oscillating behaviour of melatonin levels in 12:12-hr light/ dark cycles (Kolar et al., 1997; Arnao and Hernández-Ruiz, 2015). Low or undetectable levels of melatonin were found during the light period and a considerable increase (reaching maximum levels of $\sim 250 \mathrm{pg} / \mathrm{g}$ FW) in darkness (Kolar et al., 1997). This increase in melatonin during the dark period was similar to that observed in mammals (Kolar et al., 1997). In plants exposed to different photoperiodic cycles, no relationship between the photoperiod applied and the duration of melatonin increase was observed (Wolf et al., 2001; Kolar et al., 1997; Arnao and Hernández-Ruiz, 2015).

Cucumber seeds pretreated with melatonin improved their germination rate during chilling stress with respect to untreated seeds (Posmyk et al., 2009; Arnao and HernándezRuiz, 2015). In another case, water-stressed cucumber plants treated with melatonin showed a clear increase in the seed germination rate and root growth, which indicated that the application of melatonin minimizes induced water stress (Zhang et al., 2013; Arnao and Hernández-Ruiz, 2015).

In case of pea plants (Pisum sativum), where the application of exogenous melatonin to copper contaminated soil enhanced the tolerance and survival of plants (Tan et al., 2007; Arnao and Hernández-Ruiz, 2015). The pretreatment of seeds with melatonin reduces copper toxicity in red cabbage seedlings (Brassica oleracea ) (Posmyk et al., 2009).

Melatonin improved the survival of cryopreserved callus of the Crassulaceae Rhodiola crenulata, a traditional Tibetan herb that grows in extreme conditions of cold, low oxygen, high altitude, and intense UV radiation (Zhao et al., Arnao and Hernández-Ruiz, 2015). The presence of melatonin in both preculture and regrowth media enhanced the growth of frozen shoot explants of American elm (Ulmus americana), demonstrating the usefulness of melatonin for the long-term storage of germplasm for plant cell culture (Uchendu et al., 2013; Arnao and Hernández-Ruiz, 2015). The pre-treatment of apple seedlings (Malus hupehensis) with melatonin were subjected to salt stress, shoot height, leaf number, chlorophyll content, and electrolyte leakage, the plants were less affected by the saline stress compared with untreated plants ( $\mathrm{Li}$ et al., 2012).

Melatonin treatment of seeds of soybean (Glycine max) improved the salt and drought tolerance of plants, demonstrated the significant potential of melatonin for improving field crops, also in this species (Wei et al., 2015; Arnao and Hernández-Ruiz, 2015). Melatonin combined with ascorbic acid treatment provides salt adaption in Citrus aurantium seedlings (Kostopoulou et al., 2015; Arnao and Hernández-Ruiz, 2015). Salt stress-induced seedling growth inhibition coincides with differential distribution of serotonin and melatonin in sunflower seedling roots and cotyledons (Mukherjee et al., 2014; Arnao and Hernández-Ruiz, 2015).

Exogenous application of melatonin resulted in Vitis vinifera cuttings under water-deficient stress (Meng et al., 2014). Melatonin promotes seed germination under high salinity by regulating antioxidant systems, $\mathrm{ABA}$ and GA4 interaction in cucumber (Cucumis sativus L.) (Zhang et al., 2014; Arnao and Hernández-Ruiz, 2015). Salinity-induced by melatonin resulted in the membrane potential of Characeae (Chara australis) (Beilby et al., 2015). In case of cucumber seedlings, the external application of melatonin has also effect on nitrogen metabolism under high temperature stress (Zhao et al., 2012; Arnao and Hernández-Ruiz, 2015).

Exogenous melatonin treatments improved the resistance against several fungal/bacterial infections, causing plants to develop the diseases at a lower extent (Yin et al., 2013). Thus, Yin et al., (2013) improved the resistance of Malus prunifolia against the fungus Diplocarpon mali (Marssonina apple blotch), treating trees through their roots by irrigation with melatonin at different concentrations (from 50 to $500 \mu \mathrm{M}$ ). At 20 days, melatonin-treated apple trees showed a lower number 
of damage leaves, with a higher chlorophyll content, a more efficient photosystem II and a less defoliation that infecteduntreated trees (Yin et al., 2013). Melatonin also induced the nuclear localization of the SA receptor (NPR1), a key factor in the signaling pathway in Arabidopsis thaliana (Lee et al., 2015). Melatonin is able to induce root primordials from pericycle cells in lupin, generating new adventitious or lateral roots. This rhizogenic effect has also been studied in other species such as rice, cherry, Arabidopsis, cucumber and pomegranate (Arnao and Hernández-Ruiz, 2015). In 2004, the action of melatonin as a growth promoter was demonstrated in etiolated Lupinus albus (Arnao and Hernández-Ruiz, 2015). The growth-promoting effect of melatonin was also demonstrated in several monocots (Arnao and HernándezRuiz, 2015). The positive effect of exogenous melatonin on root/shoot growth has been clearly demonstrated in several species such as Arabidopsis, soybean, bermudagrass, and Citrus (Arnao and Hernández-Ruiz, 2015).

The effect of exogenous melatonin on ethylene metabolism, postharvest ripening, and the quality of tomato fruit showed that tomatoes treated with $50 \mu \mathrm{M}$ melatonin for $2 \mathrm{hr}$ manifested substantial changes in their fruit ripening parameters, such as lycopene levels, fruit softening, flavor, ethylene signaling, and biosynthesis enzymes with respect to untreated tomatoes (Sun et al., 2015). The exogenous melatonin treatment provoked the up-regulation of genes related with lycopene biosynthesis-, aroma/flavor-, cell wall structure, and aquaporin in tomatoes, leading to the conclusion that melatonin promotes postharvest tomato fruit ripening through increased ethylene production and signaling (Sun et al., 2015; Arnao and Hernández-Ruiz, 2015). The effect of exogenous melatonin on ethylene metabolism is also reported in etiolated seedlings of lupin and mung bean hypocotyls (Arnao and Hernández-Ruiz, 2015; Kim et al., 2001). In case of gibberellins (GA) and ABA, the levels of both plant hormones were altered by melatonin treatment (Zhang et al., 2014).

Another study reported the use of melatonin in Agrobacterium-mediated plant transformation methods (Dan et al., 2015; Arnao and Hernández-Ruiz, 2015). The presence of exogenous melatonin significantly reduced tissue browning and cell death, without affecting T-DNA integration, increasing the stable transformation frequency of plants (Dan et al., 2015; Arnao and Hernández-Ruiz, 2015).

Melatonin is involved in various physiological processes and stress responses in animals and plants ( $\mathrm{Li}$ et al., 2021). However, little is known about the molecular mechanisms by which melatonin regulates potassium deficiency (DK) tolerance in crops ( $\mathrm{Li}$ et al., 2021). The transient overexpression of TaNAC7l in wheat protoplasts activated the TaHAKl expression, whereas its transient silencing inhibited the TaHAKl expression and aggravated the sensitivity to potassium deficiency (DK) (Li et al., 2021). Exogenous melatonin application greatly upregulated the expression of TaHAKl in both transient over expression and silencing systems ( $\mathrm{Li}$ et al., 2021). Therefore, this study revealed some molecular mechanisms underlying melatonin-mediated potassium deficiency (DK) tolerance and helped its practical applications in agriculture (Li et al., 2021).

Melatonin may act directly as free radical scavenger (direct antioxidant) on ROS/RNS, lipid peroxides, and toxic chemicals, controlling relevant aspects such as membrane integrity and the proper functioning of redox network (Arnao and Hernández-Ruiz, 2015). Thus, melatonin acts as a first barrier against the ROS burst and, in a second line of defense, changes the expression of many responsive stress genes (Arnao and Hernández-Ruiz, 2015). Both abiotic and biotic stress effects are mediated by an oxidative burst, ROS induction being the first cellular signal (Arnao and Hernández-Ruiz, 2015; Kolar et al., 1995; Erland et al., 2016; Arnao and Hernández-Ruiz, 2006; Forsyth, 2020; Murch et al., 2000; Murch et al., 2001; Murch and Saxena, 2002a; Murch et al., 1997; Erland and Saxena, 2018; Erland et al., 2018a, 2018b, 2018c). Endogenous melatonin can change the expression of many genes, and regulation factors that attenuate or reverse the negative effects of biotic/abiotic stressors on physiological processes, acting in this way as a positive effector against stress (Arnao and Hernández-Ruiz, 2015). As regards the origin of melatonin, it is generated in the mitochondria and chloroplast confirmed (Arnao and Hernández-Ruiz, 2015; Arnao and Hernández-Ruiz, 2007). But roots have the highest melatonin content of the whole plant, presumably being synthesized in the leucoplastid of roots, this remains to be confirmed (Arnao and HernándezRuiz, 2015).

In Lupinus albus, both melatonin and indole-3- acetic acid induced the appearance of root primordia from pericicle cells, modifying the pattern of distribution of adventitious or lateral roots, the time-course, the number and length of adventitious roots, and the number of lateral roots (Arnao and HernándezRuiz, 2007). Melatonin and indole-3-acetic acid were detected and quantified in lupin primary roots, where both molecules were present in similar concentrations (Arnao and HernándezRuiz, 2007). The physiological effect of exogenous melatonin as root promoter was demonstrated, its action being similar to that of indole-3- acetic acid (Arnao and Hernández-Ruiz, 2007).

Kang et al., (2011) reported the cloning of $\mathrm{N}$-acetylserotonin methyltransferase (ASMT), the last enzyme in the synthesis of melatonin, catalyzes $\mathrm{N}$-acetylserotonin into melatonin in rice (Oryza sativa cv. Dongjin) (Kang et al., 2011). The cloning of ASMT from rice through the analysis of recombinant Escherichia coli harboring putative rice O-methyltransferase (OMT) cDNAs was reported (Kang et al., 2011). In another study reported by Park et al., (2012), melatonin-rich transgenic rice plants exhibited resistance to herbicideinduced oxidative stress (Park et al., 2012). This is the first report showing that melatonin rich transgenic rice plants exhibited resistance against a peroxidizing herbicide that acts by generating reactive oxygen species (ROS) that kill plants 
(Park et al., 2012). These results indicated that melatonin scavenges ROS efficiently in vivo in the transgenic rice plants, leading to the oxidative stress resistance (Park et al., 2012).

Serotonin N-acetyltransferase (SNA), a rate-limiting enzyme in melatonin biosynthesis in vertebrates, is responsible for the production of Nacetylserotonin; this molecule is then converted to melatonin by hydroxyindole-O-methyltransferase (Kang et al., 2010). Kang et al., (2010) generated transgenic rice plants via expression of the human SNA gene under the constitutive ubiquitin promoter using Agrobacteriummediated gene transformation (Kang et al., 2010). The functional expression of SNA protein was closely associated with the elevated synthesis of $\mathrm{N}$-acetylserotonin and melatonin in the transgenic rice plants (Kang et al., 2010; Park and Back,2012). Exogenous treatment of serotonin significantly enhanced melatonin biosynthesis, indicating that endogenous serotonin levels play a bottleneck role in the pathway of melatonin biosynthesis (Kang et al., 2010; Park and Back,2012). Finally, the transgenic rice seedlings with the high levels of melatonin showed elevated chlorophyll synthesis during cold stress, suggesting a role for melatonin in cold-stress resistance (Kang et al., 2010; Park and Back, 2012). The effect of melatonin on root growth after germination was examined in transgenic rice seedlings expressing serotonin $\mathrm{N}$-acetyltransferase (NAT) (Park and Back, 2012). These results indicated that melatonin plays an important role in regulating both seminal root length and root growth after germination in monocotyledonous rice plants (Park and Back, 2012). This is the first report on the effects of melatonin on root growth in gain-of-function mutant plants that produced high levels of melatonin (Park and Back, 2012).

Bidabadi et al., (2020) reported that the application of exogenous melatonin improved glutathione content, redox state and increased essential oil production in two Salvia species under drought stress (Bidabadi et al., 2020). When salvia plants were subjected to water deficit, melatonin treatment increased the concentration and composition of the essential oil (Bidabadi et al., 2020).

Melatonin also enhances the rate of germination, growth and plant productivity. Melatonin acts as a retardant in stressinduced leaf senescence (Manchester et al., 2000). The physiological concentrations of melatonin in the 15 seeds studied ranged from 2 to $200 \mathrm{ng} / \mathrm{g}$ dry weight (Manchester et al., 2000). The highest concentrations of melatonin were observed in white and black mustard seeds (Manchester et al., 2000). This level of melatonin is much higher than the known physiological concentrations in the blood of many vertebrates (Manchester et al., 2000). Since the seed, particularly its germ tissue, is highly vulnerable to oxidative stress and damage. Therefore, melatonin, acts as a free radical scavenger, might be present as an important component of its antioxidant defense system (Manchester et al., 2000). Thus, melatonin in seeds may be essential in protecting germ and reproductive tissues of plants from oxidative damage due to ultraviolet light, drought, extremes in temperature, and environmental chemical pollutants (Manchester et al., 2000).

In one of the study, evidence for the occurrence of melatonin in the roots of Glycyrrhiza uralensis plants and the response of this plant to the spectral quality of light including red, blue and white light (control) and UV-B radiation $(280-315 \mathrm{~nm}$ ) for the synthesis of melatonin were investigated (Afreen et al., 2006). Melatonin was extracted and quantified in seed, root, leaf and stem tissues and results revealed that the root tissues contained the highest concentration of melatonin; melatonin concentrations also increased with plant development (Afreen et al., 2006). The concentration of melatonin quantified in the root tissues was highest in the plants exposed to high intensity UV-B radiation for 3 days followed by low intensity UV-B radiation for 15 days (Afreen et al., 2006). The reduction of melatonin under longer periods of UV-B exposure indicated that melatonin synthesis may be related to the integrated (intensity and duration) value of UV-B irradiation (Afreen et al., 2006). Melatonin in Glycyrrhiza uralensis plant is presumably for the protection against oxidative damage caused as a response to UV irradiation (Afreen et al., 2006).

Melatonin ( $N$-acetyl-5-methoxytryptamine) was detected by a modified HPLC method and ELISA tests in extracts of eight different Vitis vinifera cultivars, namely Nebbiolo, Croatina, Sangiovese, Merlot, Marzemino, Cabernet Franc, Cabernet Sauvignon and Barbera (Iriti et al., 2006). Melatonin concentration varied greatly among the cultivars, being the highest in Nebbiolo (0.965 ng g-1) and Croatina (0.870 ng g-1) (Iriti et al., 2006). The finding of this compound in grape confirmed that the well-established pharmaconutritional properties of this fruit are due not only to the presence of polyphenolic nutraceuticals, such as resveratrol, anthocyanins and proanthocyanidins, but also to the powerful antioxidant activity of melatonin (Iriti et al., 2006).

Melatonin is present in olive oil at higher levels in extra virgin olive oil than in refined olive or sunflower oil samples (De la Puerta et al., 2007). Therefore, these experiments concluded that melatonin is the part of the phytochemical profile of the olive oil (De la Puerta et al., 2007). Particularly, extra virgin olive oil had almost double the melatonin contents of the other refined oils analysed (De la Puerta et al., 2007). Thus, melatonin may account for the healthy effects of the Mediterranean diet in which olive oil is the main source of fat (De la Puerta et al., 2007).

The melatonin contents in mulberry leaves harvested from three major cultivars (Buriram 60, Sakonnakhon and Khunphai) grown in Thailand were identified and quantified using high-performance liquid chromatography combined with fluorescence detector (Pothinuch and Tongchitpakdee, 2011). The average melatonin content of the mulberry leaves cv. Buriram 60 (279.6 ng/g dry weight (DW) was higher than those of cv. Sakonnakhon (100.5 ng/g DW) and cv. Khunphai (40.7 ng/g DW) (Pothinuch and Tongchitpakdee, 2011). The melatonin contents of all the cultivars tested were highest in 
the tip of the leaves, followed by that in the young leaves, whereas the lowest was found in the old leaves (Pothinuch and Tongchitpakdee, 2011). The melatonin contents of the two types of tea produced from mulberry leaves cv. Buriram 60 were also determined (Pothinuch and Tongchitpakdee, 2011). Heat treatment during tea processing decreased the melatonin content in mulberry leaves cv. Buriram 60 by approximately $87 \%$, when compared to that of the fresh leaves (Pothinuch and Tongchitpakdee, 2011). However, there were no significant differences between the melatonin contents of the mulberry leaf tea produced with blanching (mulberry green tea), and those produced without blanching (mulberry black tea) (Pothinuch and Tongchitpakdee, 2011).

Addition of exogenous melatonin alleviated the green macroalga Ulva species from cadmium-induced stress (Tal et al., 2011). These results provided, for the first time, an experimental data that supported both an antioxidant role for melatonin and its semi-lunar rhythm in macroalgae Ulva species (Tal et al., 2011).

The effects of melatonin (N-acetyl-5-methoxytryptamine) on the rooting of certain commercial sweet cherry rootstocks has been reported (Sarropoulou et al., 2012). Shoot tip explants from previous in vitro cultures of the cherry rootstocks CAB6P (Prunus cerasus L.), Gisela 6 (Prunus cerasus · Prunus canescens), and M - M 60 (Prunus. avium · Prunus. mahaleb) were included in the experiment (Sarropoulou et al., 2012). The data presented in this study showed that melatonin has a rooting promoting effect at a low concentration $(1 \mathrm{mg})$ but a growth inhibitory effect at high concentrations (Sarropoulou et al., 2012). In the absence of auxin, melatonin had auxinic response concerning the number and length of roots, but 10 $\mathrm{mg}$ of melatonin was inhibitory to rooting in all the tested rootstocks (Sarropoulou et al., 2012). Therefore, exogenously applied melatonin acted as a rooting promoter and its action was similar to that of IAA (Sarropoulou et al., 2012).

Melatonin has been detected and quantified in many plant species (Arnao, 2014) such as 1) Pine apple (Ananas comosus; Family- Bromeliaceae), 2) Asparagus (Asparagus officinalis L.; Family- Asparagaceae), 3) Radish (Raphanus sativus L.; Family- Brassicaceae), 4) Cabbage (Brassica oleracea capitata L.; Brassicaceae), 5) Mustard seed- Black (Brassica nigra L.; Brassicaceae), 6) Mustard seed-white (Brassica hirta L.; Brassicaceae), 7) Chinese cabbage (Brassica rapa L.; Brassicaceae), 8) Cucumber seed and fruit (Cucumis sativus L.; Cucurbitaceae), 9) Alfalfa seed (Medicago sativa L.; Fabaceae), 10) Fenugreek seed (Trigonella foenum-graecum; Fabaceae), 11) Lupin seed (Lupinus albus L.; Fabaceae), 12) Walnut (Juglans regia L.; Juglandaceae). 13) Rice seed (Oryza sativa L.; Poaceae), 14) Barley seed (Hordeum vulgare L.; Poaceae), 15) Sweet corn (Zea mays L; Poaceae), 16) Oat seed (Avena sativa L.; Poaceae), 17) Tall fescue (Festuca arundinacea Schreb; Poaceae), 18) Poppy seed (Papaver somniferum L.; Papaveraceae), 19) Onion (Allium cepa L.; Liliaceae), 20) Pomegranate( Punica granatum L.; Lythraceae), 21) Banana (Musa acuminata Colla; Musacea),
22) Olive oil (Olea europaea L.; Oleracea), 23) Apple (Malus domestica Borkh; Rosaceae), 24), Strawberry (Fragaria $x$ ananassa Duch; Rosaceae), 25), Almond seed (Prunus amygdalus Batsch; Rosaceae), 26) Tart cherries (Prunus cerasus L.; Rosaceae), 27) Sweet cherries ( Prunus avium L.; Rosaceae), 28) Coffee beans-Arabica (Coffea arabica L.; Rubiaceae), 29) Coffee beans-Robusta (Coffea canephora Pierr; Rubiaceae), 30) Orange juice (Citrus $x$ sinensis L.; Rutaceae), 31) Indian spinach (Basella alba L.; Basellaceae), 32) Taro (Colocasia esculenta L.; Araceae), 33) Beetroot (Beta vulgaris L.; Amaranthaceae), 34) Kiwi fruit (Actinidia deliciosa Liang-Ferg; Actinidiaceae), 35) Carrot (Daucus carota Hoffm; Umbelliferae), 36) Sunflower seed (Helianthus annuus L.; Umbelliferae), 37) Fennel seed (Foeniculum vulgare L.; Umbelliferae), 38) Anise seed (Pimpinella anisum L.; Umbelliferae), 39) Coriander seed (Coriandrum sativum L.; Umbelliferae), 40) Celery seed (Apium graveolens L.; Umbelliferae), 41) Linseed (flax) (Linum usitatissimum L.; Umbelliferae), 42) Tomato fruit (Solanum lycopersicum L.; Solanaceae), 43) Bell pepper: green, orange, red (Capsicum annuum L.; Solanaceae), 44) Grapevine-Red wine (Vitis vinifera L.; Vitaceae), 45) Cardamom seed (Elettaria cardamomum L.; Zingiberaceae), 46) Curcuma (Curcuma aeruginosa Roxb.; Zingiberaceae), 47) Ginger ( Zingiber officinale Rose; Zingiberaceae), 48) Date palm (Phoenix dactylifera L.; Arecaceae), 49) St. John's wort (Hypericum perforatum L.; Hypericaceae), 50) Mulberries (Morus spp. L.; Moraceae), 51) Wheat plant (Triticum aestivum L.; Poaceae), 52) Sage (Salvia officinalis L.; Lamiaceae), 53) Common fig (Ficus carica L.; Moraceae), 54) White cedar (Melia azedarach L.; Meliaceae), 55) Laurel (Laurus nobilis L.; Lauraceae), 56) Common lantana (Lantana camara L.; Verbenaceae), 57) Tobacco (Nicotiana tabacum L.; Solanaceae), 58) Sarsaparilla (Smilax aspera L.; Smilacaceae), 59) Silverleaf nightshade (Solanum elaeagnifolium Cav. Solanaceae), 60) Black nightshade (Solanum nigrum L.; Solanaceae), 61) Drug snowbell (Styrax officinalis L.; Solanaceae), 62) Narrow-leaved madder (Rubia tenuifolia D'Urv.; Rubiaceae), 63) Water hyacinth (Eicchornia crassipes Marth.; Pontederiaceae), 64) Canary grass (Phalaris canariensis L.; Poaceae), 65) Honeysuckle (Lonicera etrusca Santi; Caprifoliaceae), 66) Feverfew (Tanacetum parthenium L.; Asteraceae), 67) Red goosefoot (Chenopodium rubrum L.; Amaranthaceae), 68) Laurestine (Viburnum tinus L.; Adoxaceae), 69) Pistachio (Pistacia lentiscus L.; Anacardiaceae), 70) Cyprus turpentine (Pistacia palaestina Boiss.; Anacardiaceae), 71) Yarrow (Achillea millefolium L.; Asteraceae), 72) Ivy morning glory (Ipomoea nil L.; Convolvulaceae), 73) Honeysuckle (Lonicera etrusca Santi; Caprifoliaceae), 74) Joint fir ( Ephedra campylopoda L.; Ephedraceae), 75) White lupin (Lupinus albus L.; Fabaceae), 76) Chinese liquorice (Glycyrrhiza uralensis Fisch.; Fabaceae), 77) Bitter melon (Momordica charantia (L; Cucurbitaceae), 78) Java bean (Medicago sativu), 79) Milk thistle seed (Silybum marianum), 80) Wolf berry seed (Lycium barbarum), 81), Huang-qin (Scutellaria biacalensis) (Arnao 
and Hernández-Ruiz, 2006, 2007a, 2007b, 2008, 2015; Arnao, 2014; Fan et al., 2018; Hardeland, 2016; Hernandez-Ruiz et al., 2005; Reiter and Tan, 2002; Murch et al., 2000; Murch et al., 2001; Murch and Saxena, 2002; Murch et al., 1997; Pereira et al., 2020; Peuhkuri et al., 2012).

\section{CONCLUSION}

This review paper is developed on the basis of literature survey which highlights role of melatonin as a medicine against coronavirus (SARS-CoV-2) and physiological functions in plants. Melatonin is a ubiquitous molecule presnt in all the living kingdoms. In plants, melatonin acts as plant growth hormone and involved in plant growth, organogenesis and development. Melatonin is a light sensitive molecule used in the therapy of sleeping disorders- insomnia, glaucoma, stroke, cancers, puberty, Alzheimers disease, Parkinson disease, ultraviolet light skin damage protection, thrombocytopenia, in smoking cessation, headache protection, migrane, and as an antioxidant. General immunity is impaired by anxiety and sleep deprivation. Melatonin improves sleep habits, reduces anxiety and stimulates immunity. Light is the dominant environmental factor that controls melatonin synthesis. The use of dietary melatonin may be extremely beneficial in helping to maximize the health-promoting efects of medicinal plants and healthy foods in humans, possibly acting in synergy with other bioactive phytochemicals (i.e., polyphenols) that are ingested daily.

Melatonin produced by the pineal gland is released into the circulation and gains access to various fluids, tissues and cellular compartments. Because this highly lipophilic hormone is not stored in the pineal gland, the profile of its plasma levels reflects pineal activity. More than $90 \%$ of circulating melatonin is deactivated by the liver and finally excreted in urine.

Melatonin is a pleiotropic molecule with multiple functions. In recent years, there has been a considerable increase in the consumption of melatonin supplements since melatonin is related with sleep (as an antioxidant, for anti-aging, and as a hunger regulator). The consumption of food sources of melatonin is associated with health benefits, significantly increasing serum concentrations and raising the antioxidant capacity in humans, being therefore considered a nutraceutical. However, the current lack of knowledge on the oral bioavailability of melatonin in the humans diet clearly indicated the need for more in-depth clinical trials, namely considering the circadian and seasonal variations of endogenous melatonin and allowing to estimate the amount of melatonin ingested. However, there is no difference between endogenous and exogenously acquired melatonin, it is very difficult to assess the dietary contribution in humans. Some plant tissues contain melatonin and therefore, the consumption of such tissues could alter blood melatonin levels and offer antioxidant protection in addition to endogenously produced melatonin.

\section{REFERENCES}

[1] Acuna-Castroviejo D, Escames G, Figueira JC, de la Oliva P, Borobia AM, Acuna- Fernandez C (2020) Clinical trial to test the efficacy of melatonin in COVID-19. J Pineal Res. 69:e12683.

[2] Adhikary D, Forsyth JA, Murch SJ, Deyholos MK (2020) Impact of betacyanins on responses to ultraviolet radiation in Amaranthus tricolor L. J. Plant Interact. Accepted.

[3] Afreen F, Zobayed SMA, Kozai T (2006) Melatonin in Glycyrrhiza uralensis: Response of plant roots to spectral quality of light and UV-B radiation. J. Pineal Res. 41:108-115. (Doi:10.1111/j.1600-079X.2006.00337.x).

[4] Aher VD, Wahi AK (2011) Melatonin: A novel biomaterial for immunotherapy International Journal of Pharmaceutical Sciences and Research. 2(4): 772-777.

[5] Akula R, Parvatam G, Kadimi US et al., (2012) Melatonin and serotonin profile in beans of Coffea species. J. Pineal Res. 52(4):470-76.

[6] Ali MAA (2020) Avoiding room light during night may stimulate immunity in COVID-19 patients by promoting melatonin production. Melatonin Res. 3: 476-481.

[7] Anderson G, Reiter RJ (2020) Melatonin: Roles in influenza, Covid-19, and other viral infections. Rev Med Virol. (doi: 10.1002/rmv.2109).

[8] Anderson G, Maes M, Markus RP, Rodriguez M (2015) Ebola virus: Melatonin as a readily available treatment option. J. Med. Virol. 87: 537-543.

[9] Anderson GM (2021) Fluvoxamine, melatonin and COVID19. Psychopharmacology. 238: 611 (https://doi.org/10.1007/s00213-020-05753-z).

[10] Anisimov VN (2002) The light-dark regimen and cancer development. Neuroendocrinology Letters. 23:28-36.

[11] Ansari M, Rafiee KH, Yasa N, Vardasbi S, Naimi SM, Nowrouzi A (2010) Measurement of melatonin in alcoholic and hot water extracts of Tanacetum parthenium, Tripleurospermum disciforme and Viola odorata. DARU. 18(3): 173-177.

[12] Arnao MB, Hernández-Ruiz J (2006) The Physiological function of melatonin in plants. Plant Signaling \& Behavior. 1(3): 89-95. ( DOI: 10.4161/psb.1.3.2640).

[13] Arnao MB, Hernández-Ruiz J (2007a) Melatonin promotes adventitious-and lateral root regeneration in etiolated hypocotyls of Lupinus albus L. J. Pineal Res. 42:147-152. (Doi:10.1111/j.1600-079X.2006.00396.x).

[14] Arnao MB, Hernández-Ruiz J (2007b) Melatonin in plants. Plant Signaling \& Behavior. 2(5): 381-382.

[15] Arnao MB, Hernández-Ruiz J (2008) Assessment of different sample processing procedures applied to the determination of melatonin in plants. Phytochem. Anal. 20: 14-18.

[16] Arnao MB (2014) Phytomelatonin: Discovery, content, and role in plants. Hindawi Publishing Corporation Advances in Botany. Volume 2014, Article ID 815769, 1-11. (http://dx.doi.org/10.1155/2014/815769).

[17] Arnao MB, Hernández-Ruiz J (2015) Functions of melatonin in plants: A review. J. Pineal Res. 59:133150.(Doi:10.1111/jpi.12253).

[18] Atanu B, Shastry CS, Santanu S (2014) Isolation, purification and structural elucidation of N-acetyl-5- methoxytryptamine (Melatonin) from Crataeva nurvala Buch-Ham stem bark. AJPCT. 2(3):301-09.

[19] Ayushi J, Maheep B (2007) Melatonin-a "magic biomolecule". Ann Neurosci. 14(4):1-5.

[20] Badria F (2002) "Melatonin, serotonin, and tryptamine in some Egyptian food and medicinal plants." Journal of medicinal food. 5(3): 153-157.

[21] Bae SM, Jeong J, Jeon JJ (2016) Effects of melatonin-Rich milk on mild insomnia symptoms. Sleep Medicine Research. 7(2): 6067. (https://doi.org/10.17241).

[22] Balzer B, Hardeland R (1991) Photoperiodism and effects of indoleamines in a unicellular alga, Gonyaulax polyedra. Science. 253:795-7. 
[23] Balzer I, Hardeland R (1996) Melatonin in algae and higher plants Possible new roles as a phytohormone and antioxidant. Bot Acta. 109:180-3.

[24] Bajwa VS, Shukla MR, Sherif SM et al., (2014) Role of melatonin in alleviating cold stress in Arabidopsis thaliana. J Pineal Res. 56:238-245.

[25] Beilby MJ, AL Khazaaly S, Bisson MA (2015) Salinity-induced noise in membrane potential of Characeae Chara australis: Effect of exogenous melatonin. J. Membr Biol. 248:93-102.

[26] Benot S, Goberna R, Reiter RJ, Garcia-Mauriño S, Osuna C, Guerrero JM (1999) Physiological levels of melatonin contribute to the antioxidant capacity of human serum. J Pineal Res. 27:5964.

[27] Bhattacharjee A, Dey BK (2018) Phytomelatonin: A comprehensive literature review and recent advance on medicinal meadow. International Journal of Hydrology. 2(3): 396-403. (DOI: 10.15406/ijh.2018.02.00102).

[28] Bidabadi SS, Weide JV, Sabbatini P (2020) Exogenous melatonin improves glutathione content, redox state and increases essential oil production in two Salvia species under drought stress. Scientific Reports. 10:6883. ( https://doi.org/10.1038/s41598-02063986-6).

[29] Blask DE, Sauer LA, Dauchy RT (2002) Melatonin as a chronobiotic/anticancer agent: Cellular, biochemical, and molecular mechanisms of action and their implications for circadian-based cancer therapy. Curr Topics in Med Chem. 2:113132.

[30] Bob P, Fedor-Freybergh P ( 2008) Melatonin, consciousness, and traumatic stress. J. Pineal Res. 44:341-347.

[31] Boccalandro HE, González CV, Wunderlin DA, Silva MF (2011) Melatonin levels, determined by LC-ESI-MS/MS, fluctuate during the day/night cycle in Vitis vinifera cv Malbec: Evidence of its antioxidant role in fruits. J. Pineal Res. 51:226-232. (https://doi.org/10.1111/j.1600-079X.2011.00884.x).

[32] Bonnefont-Rousselot D, Collin F (2010) Melatonin: Action as antioxidant and potential applications in human disease and aging. Toxicology. 13 (7):

[33] Brazaityte A, Sakalauskiene S, Samuoliene G, Jankauskiene J, Viršile A, Novičkovas A, Sirtautas R, Miliauskiene J, Vaštakaite V, Dabašinskas L, Duchovskis P (2015) The effects of LED illumination spectra and intensity on carotenoid content in Brassicaceae micro greens. Food Chem. 173: 600-606. (https://doi.org/10.1016/j.foodchem.2014.10.077).

[34] Brusco L, Brusco L, Cruz P, Cangas A, Rojas C, Vigo D, Cardinali D (2021) Efficacy of melatonin in non intensive care unit patients with COVID-19 pneumonia and sleep dysregulation. Melatonin Research. 4 (1) : 173-188. (DOI:https://doi.org/https://doi.org/10.32794/mr11250089).

[35] Brzezinski A (1997) Melatonin in humans. N. Engl. J. Med. 336:186-95.

[36] Burkhardt S, Tan DX, Manchester LC, Hardeland R, Reiter RJ (2001) Detection and quantification of the antioxidant melatonin in montmorency and balaton tart cherries. J Agric Food Chem. 49:4898-902.

[37] Byeon Y, Park S, Kim YSS, Park, DHH, Lee S, Back K (2012) Light-regulated melatonin biosynthesis in rice during the senescence process in detached leaves. J. Pineal Res. 53: 107-111. (https://doi.org/10.1111/j.1600-079X.2012.00976.x).

[38] Caliskan UK, Ceylan AKA, Emrah BOR (2017) Melatonin in edible and non-edible plants. Turk J Pharm Sci. 14(1):75-83.

[39] Carrillo-Vico A, Guerrero JM, Lardone PJ, Reiter RJ (2005) A Review of the multiple actions of melatonin on the immune system. Endocrine. 27( 2): 189-200.

[40] Cappuccio FP, D'Elia L, Strazzullo P, Miller MA (2010). Quantity and quality of sleep and incidence of type 2 diabetes. Diabetes Care. 33(2): 414-420. (https://doi.org/10.2337/dc091124).

[41] Cardinali DP, Brown GM, Pandi-Perumara SR (2020) Can melatonin be a potential "Silver Bullet" in treating COVID-19 patients?. Diseases. 8(44) 2-15. (doi:10.3390/diseases8040044).
[42] Cardinali DPDA, Golombek RE, Rosenstein RA, Cutrera A, Esquifino AI (1997) "Melatonin site and mechanism of action: Single or multiple?". Journal of Pineal Research. 23(1): 32-39.

[43] Castro N, Spengler M, Lollivier V, Wellnitz O, Meyer HHD, Bruckmaier RM (2011) Diurnal pattern of melatonin in blood and milk of dairy cows. Milchwiss-Milk Sci Int. 66: 352-3.

[44] Chen G, Huo Y, Tan DX, Liang Z, Zhang W, Zhang Y (2003) Melatonin in Chinese medicinal herbs. Life Sci. 73:19-26.

[45] Chen J, Li H, Yang K, Wang Y, Yang L, Hu L, Liu R, Shi Z (2019) Melatonin facilitates lateral root development by coordinating PAO-derived hydrogen peroxide and Rboh-derived superoxide radical. Free Radic. Biol. Med. 143: 534-544. (https://doi.org/10.1016/j.freeradbiomed.2019.09.011).

[46] Cui G, Zhao X, Liu S, Sun F, Zhang C, Xi Y (2017) Beneficial effects of melatonin in overcoming drought stress in wheat seedlings. Plant Physiol. Biochem. 118: 138-149. (https://doi.org/10.1016/j.plaphy.2017.06.014).

[47] Dan Y, Zhang S, Zhong H et al., (2015) Novel compounds that enhance Agrobacterium-mediated plant transformation by mitigating oxidative stress. Plant Cell Rep. 34:291-309.

[48] Daugaard S, Garde AH, Bonde JPE, Cristoffersen J, Hansen AM, Markvart J, Kolstad HA (2017) Night work, light exposure and melatonin on work days and days off. Chronobiology International. 34(7): 942-955. (https://doi.org/ 10.1080/07420528.2017.1327867).

[49] De la Puerta C, Carrascosa-Salmoral MP, Garcia-Luna PP, Lardone PJ, Herrera JL, Fernandez-Montesinos R, Guerrero JM, Pozo D (2007) Melatonin is a phytochemical in olive oil. Food Chemistry. 104: 609-612.

[50] Długosz-Grochowska O, Wojciechowska R, Kruczek M, Habela A (2017) Supplemental lighting with LEDs improves the biochemical composition of two Valerianella locusta (L.) cultivars. Hortic. Environ. Biotechnol. 58: 441-449. (https://doi.org/10.1007/s13580-017-0300-4).

[51] Dubbels R, Reiter RJ, Klenke E, Goebel A, Schnakenberg, E, Ehlers C et al., (1995) Melatonin in edible plants identified by radioimmunoassay and by high performance liquid chromatography-mass spectrometry. J. Pineal Res. 18:28-31.( doi:10.1111/j.1600-079X.1995.tb00136.x).

[52] Erland LA, Murch, SJ, Reiter RJ, Saxena PK (2015) A new balancing act: The many roles of melatonin and serotonin in plant growth and development. Plant Signal. Behav. 10:e1096469. (doi: 10.1080/15592324.2015.1096469).

[53] Erland LAE, Chattopadhyay A, Jones AMP and Saxena PK (2016) Melatonin in plants and plant culture systems: Variability, stability and efficient quantification. Front. Plant Sci. 7:1721. (doi: 10.3389/fpls.2016.01721).

[54] Erland LAE, Saxena PK (2018) Melatonin in plant morphogenesis. Vitr. Cell. Dev. Biol. - Plant 54: 3-24. (https://doi.org/10.1007/s11627-017-9879-5).

[55] Erland LAE, Saxena PK, Murch SJ (2018a) Melatonin in plant signalling and behaviour. Funct. Plant Biol. 45: 58-69. (https://doi.org/10.1071/FP16384).

[56] Erland LAE, Shukla MR, Singh AS Murch SJ, Saxena PK (2018b) Melatonin and serotonin: Mediators in the symphony of plant morphogenesis. J. Pineal Res. 64: e12452. (https://doi.org/10.1111/jpi.12452).

[57] Erland LAE, Yasunaga A, Li ITS, Murch SJ, Saxena PK (2018c) Direct visualization of location and uptake of applied melatonin and serotonin in living tissues and their redistribution in plants in response to thermal stress. J. Pineal Res. e12527. (https://doi.org/10.1111/jpi.12527).

[58] Fan J, Xie Y, Zhang Z, Chen L (2018) Melatonin: A multifunctional factor in plants. Int. J. Mol. Sci. 19. (https://doi.org/10.3390/ijms19051528).

[59] Feitosa EL, Junior FTDSS, Nery Neto JADO, Matos LFL, Moura MHDS, Rosales TO, De Freitas GBL (2020) Covid-19: Rational discovery of the therapeutic potential of melatonin as a SARSCoV-2 main protease inhibitor. Int Med Sci. 17(14):2133-2146. (doi:10.7150/ijms.48053). 
[60] Fernandes PA, Kinker GS, Navarro BV, Jardim VC, Ribeiro-Paz ED, Córdoba-Moreno MO, Santos-Silva D, Muxel SM, Fujita A, Moraes C, Nakaya HI, Buckeridge MS, Markus RP (2021) Melatonin-Index as a biomarker for predicting the distribution of presymptomatic and asymptomatic SARS-CoV-2 carriers. Melatonin Research. 4 (1): 189-205. (DOI:https://doi.org/https://doi.org/10.32794/mr1125009).

[61] Fischer TW, Slominski A, Zmijewski MA, Reiter RJ, Paus R (2008) Melatonin as a major skin protectant: From free radical scavenging to DNA damage repair. Experimental Dermatology. 17: 713-730.

[62] Foulkes NS, Borjigin J, Snyder SH, Sassone-Corsi P (1997) Rhythmic transcription: The molecular basis of circadian melatonin synthesis. Trends Neurosci. 20:487-92.

[63] Fuhrberg B, Hardeland R, Poeggeler B, Behrmann G (1995) Melatonin rises dramatically in Gonyaulax polyedra exposed to decreased temperature: Implications for photoperiodic cyst induction. Biol Rhythm Res. 26:391-6.

[64] Fuhrberg B, Balzer I, Hardeland R, Werner A, Luning K (1996) The vertebrate pineal hormone melatonin is produced by the brown alga Pterygophora californica and mimics dark effects on growth rate in the light. Planta. 200:125-31.

[65] Fuhrberg B, Hardeland R, Poeggeler B, Behrmann G (1997) Dramatic rises of melatonin and 5-methoxytryptamine in Gonyaulax exposed to decreased temperatures. Biol Rhythm Res. 28:144-50.

[66] Forsyth JA (2020) Melatonin is a light signalling molecule in plants. Thesis submitted in partial fulfillment of the requirements for the degree of Master of Science in the college graduate studies (chemistry). 1-124. The University of British Columbia, Okanagan, BC, Canada.

[67] Forsyth JA, Erland LAE, Shipley PR, Murch SJ (2020) Plant perception of light: The 103 role of indoleamines in Scutellaria species. Melatonin Res. 3: 161-176. (https://doi.org/https://doi.org/https://doi.org/10.32794/mr1125005 4).

[68] Gong B, Yan Y, Wen D, Shi Q (2017) Hydrogen peroxide produced by NADPH oxidase: A novel downstream signaling pathway in melatonin-induced stress tolerance in Solanum lycopersicum. Physiol. Plant. 160: 396-409. (https://doi.org/10.1111/ppl.12581).

[69] Gurunathan S, Kang MH, Choi Y, Reiter RJ, Kim JH ( 2021) Melatonin: A potential therapeutic agent against COVID-19. Melatonin Res. 4 (1) 30-69. (doi: 10.32794/mr11250081).

[70] Haldar C, Ahmad R (2010) Photoimmunomodulation and melatonin. Journal of Photochemistry and Photobiology B: Biology. 98: 107-117.

[71] Hansen AL, Dahl L, Olson G, Thomton D, Graff IE, Froyland L, Pallesen S (2014) Fish consumption, sleep, daily functioning, and heart rate variability. Journal of Clinical Sleep Medicine. 10(5): 567-575. ( https://doi.org/110.5664/jcsm.3714).

[72] Hardeland R, Pandi-Perumal SR (2005) Melatonin, a potent agent in antioxidative defense: Actions as a natural food constituent, gastrointestinal factor, drug and prodrug. Nutrition and Metabolism. 2:22. (doi:10.1186/1743-7075-2-22).

[73] Hardeland R (2016) Melatonin in plants-diversity of levels and multiplicity of functions. Front. Plant Sci. 7:198. (doi:10.3389/fpls.2016.00198).

[74] Hardeland R, Poeggeler B (2003) Nonvertebrate melatonin. J Pineal Res. 34:233-41.

[75] Hardeland R, Fuhrberg B (1996) Ubiquitous melatonin: Presence and effects in unicells, plants and animals. Trends Comp Biochem Physiol. 2:25-45.

[76] Hardeland R, Reiter RJ, Poeggeler B, Tan DX (1993) The significance of the metabolism of the neurohormone melatonin: Antioxidative protection and formation of bioactive substances. Neurosci Biobehav Rev. 17:347-57.

[77] Hardeland R, Pandi-Perumal SR, Cardinali DP (2006) Molecules in focus melatonin. The International Journal of Biochemistry and Cell Biology. 38 : 313-316.
[78] Harumi T, Matsushima S (2000) Separation and assay methods for melatonin and its precursors. J Chromatogr B. 747:95-110.

[79] Hattori A, Migitaka H, ligo M, Itoh M, Yamamoto K, OhtaniKaneko R et al., (1995) Identification of melatonin in plants and its effects on plasma melatonin levels and binding to melatonin receptors in vertebrates. Biochem. Mol. Biol. Int. 35(3):627-634.

[80] Hernandez-Ruiz J, Cano A, Arnao MB (2005) Melatonin acts as a growth-stimulating compound in some monocot species. J Pineal Res. 39:137-42.

[81] Hernandez-Ruiz J, Arnao MB (2008a) Melatonin stimulates the expansion of etiolated lupin cotyledons. Plant Growth Regul. 55: 29-34. (https://doi.org/10.1007/s10725-008-9254-y).

[82] Hernandez-Ruiz J, Arnao MB (2008b) Distribution of melatonin in different zones of lupin and barley plants at different ages in the presence and absence of light. J. Agric. Food Chem. 56: 1056710573.

[83] Iriti M, Rossoni M, Faoro F (2006) Melatonin content in grape: Myth or panacea?. Journal of the Science of Food and Agriculture. 86:1432-1438.

[84] Juybaria KB, Pourhanifehb MH, Hosseinzadehb A, Hematic K, Mehrzadib S (2020) Melatonin potentials against viral infections including COVID-19: Current evidence and new findings. Virus Research. 287 (2): 198108.

[85] Kang K, Lee K, Park S, Kim YS, Back K (2010) Enhanced production of melatonin by ectopic overexpression of human serotonin $\mathrm{N}$-acetyltransferase plays a role in cold resistance in ransgenic rice seedlings. J. Pineal Res. 49:176-182. (Doi:10.1111/j.1600-079X.2010.00783.X)

[86] Kang K, Kong K, Park S, Natsagdorj U, Kim YS, Back K (2011) Molecular cloning of a plant $\mathrm{N}$-acetylserotonin methyltransferase and its expression characteristics in rice. J. Pineal Res. 50:304309. (Doi:10.1111/j.1600-079X.2010.00841.x).

[87] Khan T, Ullah MA, Garros L, Hano C, Abbasi BH (2019) Synergistic effects of melatonin and distinct spectral lights for enhanced production of anti-cancerous compounds in callus cultures of Fagonia indica. J. Photochem. Photobiol. B Biol. 190: 163-171. (https://doi.org/10.1016/j.jphotobiol.2018.10.010).

[88] Karunanithi D, Radhakrishna A, Silvaraman KP, Biju VM (2014) Quantitative determination of melatonin in milk by LC-MS/MS. Journal of Food Science and Technology. 51(4): 805-812. (https://doi.org/110.1007/s13197-013-1221-6).

[89] Karasek M, Winczyk K (2006) Melatonin in humans. J Physiol Pharmacol. 57(5): S19-39.

[90] Kim JE, Kim WT, Kang BG (2001) IAA and N6-Benzyladenine inhibit ethylene-regulated expression of ACC oxidase and ACC synthase genes in mungbean hypocotyls. Plant Cell Physiol. 42:1056-1061.

[91] Kim M, Seo H, Park C, Park WJ (2016) Examination of the auxin hypothesis of phytomelatonin action in classical auxin assay systems in maize. J. Plant Physiol. 190: 67-71. (https://doi.org/10.1016/j.jplph.2015.11.009).

[92] Kolar J, Machackova I, Illnerova H, Prinsen E, van Dongen W, van Onckelen HA (1995) Melatonin in higher plant determined by radioimmunoassay and high performance liquid chromatographymass spectrometry-mass spectrometry. Biol Rhythm Res. 26:4069.

[93] Kolar J, Machackova I (2005) Melatonin in higher plants: Occurrence and possible functions. J. Pineal Res. 39:333-341. (Doi:10.1111/j.1600-079X.2005.00276.X).

[94] Kolar J, Johnson CH, Machácková I (2002) Presence and possible role of melatonin in a short-day flowering plant, Chenopodium rubrum, in: Melatonin after four decades. pp. 391-393.

[95] Kolar J, Machackova I, Eder J, Prinsen E, van Dongen W, van Onckelen H, Illnerova H (1997) Melatonin: Occurrence and daily rhythm in Chenopodium rubrum. Phytochemistry. 44:1407-1413.

[96] Kolar J, Johnson CH, Machackova I (2003) Exogenously applied melatonin affects flowering of the short-day plant Chenopodium rubrum. Physiol Plant. 118:605-12.

[97] Korkmaz A, Karaca A, Kocaçinar, F, Cuci Y (2017a) The effects of seed treatment with melatonin on germination and emergence performance of pepper seeds under chilling stress | Melatonin 
Uygulamalarının Üşüme Stresi Altındaki Biber Tohumlarının Cimlenme ve Çıııs Performansı Üzerine Etkisi. Tarim Bilim. Derg. 23: 167-176.

[98] Korkmaz, A, Yakupoglu G, Koklu S, Cuci Y, Kocaçinar F, Yakupoglu G, Koklu S, Cuci Y, Kocacinar F (2017b) Determining diurnal and seasonal changes in melatonin and tryptophan contents of eggplant (Solanum melongena L.). Turk. J. Botany. 41: 356-366. (https://doi.org/10.3906/bot-1611-48).

[99] Koritala BSC, Porter KI, Arshad OA, Gajula RP, Mitchell HD et al., (2021) Night shift schedule causes circadian dysregulation of DNA repair genes and elevated DNA damage in humans. J. Pineal Res. (https://doi.org/10.1111/jpi.12726).

[100] Kostopoulou Z, Therios I, Roumeliotis E et al., (2015) Melatonin combined with ascorbic acid provides salt adaptation in Citrus aurantium L. seedlings. Plant Physiol Biochem. 86:155165.

[101] Kleszczynski K, Slominski AT, Steinbrink K, Reiter RJ (2020) Clinical trials for use of melatonin to fight against COVID-19 are urgently needed. Nutrients. 12: 2561. (doi:10.3390/nu12092561).

[102] Kwon KJ, Kim JN, Kim MK, Lee J, Ignarro LJ, Kim HJ, Shin CY, Han SH (2011) Melatonin synergistically increases resveratrol-induced heme oxygenase-1 expression through the inhibition of ubiquitindependent proteasome pathway: A possible role in neuroprotectio. J. Pineal Res. 50:110-123. (Doi:10.1111/j.1600-079X.2010.00820.x).

[103] Lang MJ (2008) Melotonin in Tart Cherries: Methods of Extraction and Detection. A Thesis presented to the Faculty of the graduate school of Cornell University in partial fulfillment of the requirements for the degree of Master of Science. 1-70.

[104] Lazar D, Murch SJ, Beilby MJ, Al Khazaaly S (2013) Exogenous melatonin affects photosynthesis in characeae Chara australis. Plant Signal. Behav. 8: 1-5.

[105] Lee HY, Back K (2018) Melatonin induction and its role in high light stress tolerance in Arabidopsis thaliana. J. Pineal Res. 65. (https://doi.org/10.1111/jpi.12504).

[106] Lee HY, Byeon Y, Tan DX et al., (2015) Arabidopsis serotonin Nacetyltransferase knockout mutant plants exhibit decreased melatonin and salicylic acid levels resulting in susceptibility to an avirulent pathogen. J Pineal Res. 58:291-299.

[107] Lei XY, Zhu RY, Zhang GY, Dai YR (2004) Attenuation of coldinduced apoptosis by exogenous melatonin in carrot suspension cells: The possible involvement of polyamines. J Pineal Res. 36:126-31.

[108] Lerner AB, Case JD, Mori W, Wright MR (1959) "Melatonin in peripheral nerve." Nature. 183 (4678): 1821.

[109] Lerner AB, Case JD, Takahashi Y, Lee TH, Mori W (1958) Isolation of melatonin, a pineal factorthat lightens melanocytes. J. Am. Soc. 80:2587.

[110] Li C, Tan D, Liang D, Chang C, Jia D, Ma F (2015) Melatonin mediates the regulation of $\mathrm{ABA}$ metabolism, free-radical scavenging, and stomatal behaviour in two Malus species under drought stress. J. Exp. Bot. 66: 669-680. (https://doi.org/10.1093/jxb/eru476).

[111] LI C, Wang P, Wei Z et al., (2012) The mitigation effects of exogenous melatonin on salinity-induced stress in Malus hupehensis. J Pineal Res. 53:298-306.

[112] Li D, Wei J, Peng Z, Ma W, Yang Q, Song Z, Sun W, Yang W, Yuan L, Xu X, Chang W, Rengel Z, Shen J, Reiter RJ, Cui X, Yu D, Chen Q (2020) Daily rhythms of phytomelatonin signaling modulate diurnal stomatal closure via regulating reactive oxygen species dynamics in Arabidopsis. J. Pineal Res. 68. (https://doi.org/10.1111/jpi.12640).

[113] Li D, Guo Y, Zhang D, He S, Gong J, Ma H, Gao X, Wang Z, Jiang L, Dun X, Shengwu Hu S, Chen M (2020) Melatonin represses oil and anthocyanin accumulation in seeds. Plant Physiology. 183: 898-914. (www.plantphysiol.org).

[114] Li GZ, Liu J, Chen SJ, Wang PF, Liu HT, Dong J, Zheng YX, Xie YX, Wang CY, Guo TC, Kang GZ (2021) Melatonin promotes potassium deficiency tolerance by regulating HAK1 transporter and its upstream transcription factor NAC71 in wheat. J. Pineal Res. (https://doi.org/10.1111/jpi.12727).
[115] Lin HH, Tsai PS, Fang SC, Liu JF (2011) Effect of kiwifruit consumption on sleep quality in adults with sleep problems. Asia Pacific Journal of Clinical Nutrition. 20: 169-174.

[116] Lombo L, Singh J, Johnson PA, Johnson JC, Mardon AA (2021). Perceived Isolation and Health: Does isolation and feeling of loneliness pose a risk for severe SARS-CoV-2 infection?. Academia Letters. Article 139. (https://doi.org/10.20935/AL139).

[117] Lissoni $P$ (2002) Is there a role for melatonin in supportive care? Supportive Care in Cancer. 10:110-116.

[118] Lissoni P, Barni S, Tancini G, et al (1987) Clinical study of melatonin in untreatable advanced cancer patients. Tumori. 73:475-480.

[119] Lissoni P, Barni S, Ardizzoia A, et al., (1992) Randomized study with the pineal hormone melatonin versus supportive care alone in advanced nonsmall cell lung cancer resistant to a first-line chemotherapy containing cisplatin. Oncology. 49:336-339.

[120] Luchetti F, Canonico B, Betti M, Arcangeletti, M, Pilolli F, Piroddi M, Canesi L, Papa S, Galli F (2010) Melatonin signaling and cell protection function. FASEB J. 24: 3603-3624 www.fasebj.org

[121] Lundmark PO, Pandi-Perumal SR, Srinivasan V, Cardinali DP, Rosenstein RE (2007) Melatonin $\mathrm{n}$ the eye: Implications for glaucoma. Experimental Eye Research. 84: 1021-1030.

[122] Maestroni, GJM (2000) Therapeutic potential of melatonin in immunodeficiency states, viral diseases, and cancer. In Advances in Experimental Medicine and Biology; Springer: Boston, MA, USA, 2000; Volume 467, pp. 217-226. 22.

[123] Maharaj DS, Anoopkumar-Dukie S, Glass BD, Antunes EM, B. Lack B, Walker RB, Daya S (2002) "The identification of the UV degradants of melatonin and their ability to scavenge free radicals." Journal of Pineal Research. 32(4): 257-261.

[124] Malabadi RB, Meti NT, Chalannavar RK (2021) Role of herbal medicine for controlling coronavirus (SARS-CoV-2) disease (COVID-19). International Journal of Research and Scientific Innovation (IJRSI). VIII (II): 135-165.

[125] Malabadi RB, Meti NT, Chalannavar RK (2021) Applications of nanotechnology in vaccine development for coronavirus (SARSCoV-2) disease (Covid-19). International Journal of Research and Scientific Innovation. (Accepted and still in press).

[126] Maldonado MD, Moreno H, Calvo JR (2009) Melatonin present in beer contributes to increase the levels of melatonin and antioxidant capacity of the human serum. Clin Nutr. 28: 188-91.

[127] Manchester LC, Tan DX, Reiter RJ, Park W, Monis K, Qi W (2000) High levels of melatonin in the seeds of edible plants. Possible function in germ tissue protection. Life Sci. 67:3023-9.

[128] Mayo JC, Sainz RM, Tan DX, Hardeland R, Leon J, Rodriguez C, Reiter RJ (2005) "Anti-inflammatory actions of melatonin and its metabolites, N1-Acetyl-N2-Formyl-5-methoxykynuramine (Afmk) and N1-Acetyl-5-methoxykynuramine (Amk), in macrophages." Journal of Neuroimmunology. 165(1-2): 139-149.

[129] Mayo JC, Sainz RM, Tan DX, Antolín I, Rodríguez C, Reiter RJ (2005) Melatonin and Parkinson's disease. Endocrine. 27( 2): $169-178$

[130] Meng X, Li Y, Li S, Zhou Y, Gan RY, Xu DP, Li HB (2017) Dietary sources and bioactivities of melatonin. Nutrients. 9(4):164. (https://doi.org/10.3390/nu9040367).

[131] Meng JF, Xu TF, Wang ZZ et al., (2014) The ameliorative effects of exogenous melatonin on grape cuttings under water-deficient stress: Antioxidant metabolites, leaf anatomy, and chloroplast morphology. J Pineal Res. 57:200-212.

[132] Milagres MP, Minim VP, Minin LA, Simiqueli AA, Moraes LE, Martino HS (2014) Night milking adds value to cow's milk. Journal of the Science of Food and Agriculture. 94: 1688-1692. (https://doi.org/10.1002/jsfa.6480).

[133] Morera AL, Abreu P (2006) "Seasonality of psychopathology and circannual melatonin Rhythm." Journal of Pineal Research. 41(3): 279- 283.

[134] Mukherjee S, David A, Yadav S et al., (2014) Salt stress-induced seedling growth inhibition coincides with differential distribution of serotonin and melatonin in sunflower seedling roots and cotyledons. Physiol Plant. 152:714-728. 
[135] Mukherjee S (2018) Novel perspectives on the molecular crosstalk mechanisms of serotonin and melatonin in plants. Plant Physiol. Biochem. 132:

$33-45$. (https://doi.org/10.1016/j.plaphy.2018.08.031)

[136] Murch SJ, Simmons CB, Saxena PK (1997) Melatonin in feverfew and other medicinal plants. Lancet. 350: 1598-1599.

[137] Murch SJ (2000) Identification and characterization of melatonin in medicinal plants: feverfew, Huang-qin and St. John's wort $\mathrm{Ph} . \mathrm{D}$. thesis, University of Guelph, Guelph, Ontario, Canada; 2000.

[138] Murch SJ, KrishnaRaj S, Saxena PK (2000) Tryptophan is a precursor for melatonin and serotonin biosynthesis in in vitro regenerated St. Johns Wort (Hypericum perforatum L. cv. Anthos) plants. Plant Cell Rep. 19: 698-704. (https://doi.org/10.1007/s002990000206).

[139] Murch SJ, Campbell SSB, Saxena PK (2001) The role of serotonin and melatonin in plant morphogenesis: Regulation of auxininduced root organogenesis in in vitro-cultured explants of St. John's wort (Hypericum perforatum L.). Vitr. Cell. Dev. Biol. Plant. (https://doi.org/10.1007/s11627-001-0130-y).

[140] Murch SJ, Saxena PK (2002b) Mammalian neurohormones: Potential significance in sexual and asexual reproduction of St. John_s wort (Hypericum perforatum L.)? Naturwissenschaften. 89:555-560.

[141] Murch SJ, Saxena PK (2002a) Melatonin: A potential regulator of plant growth and development?. Vitr. Cell. Dev. Biol. - Plant. 38: 531-536. (https://doi.org/10.1079/IVP2002333).

[142] Murch SJ, Vasantha-Rupasinghe HP, Goodenowe D, Saxena PK (2004) A metabolomic analysisof medicinal diversity in Huangqin (Scutellaria baicalensis Georgi) genotypes: Discovery of novel compounds. Plant Cell Rep. 23:419-25.

[143] Murch SJ, Saxena PK (2006) A melatonin-rich germplasm line of St John's wort (Hypericum perforatum L.). J. Pineal Res. 41:284287. (Doi:10.1111/j.1600-079X.2006.00367.x).

[144] Murch SJ, Alan AR, Cao J, Saxena PK (2009) Melatonin and serotonin in flowers and fruits of Datura metel L. J. Pineal Res. 47:277-283. (Doi:10.1111/j.1600-079X.2009.00711.x).

[145] Murcia GJ (2002). "Puberty and Melatonin." Anales Espanoles de Pediatria. (57): 121-126.

[146] Neri B, de Leonardis V, Gemelli MT, et al., (1998) Melatonin as biological response modifier in cancer patients. Anticancer Res. 18:1329-1332.

[147] Nicasio MDP, Villrreal ML, Gillet F, Bensaddek L, Fliniaux MA (2005) Variation in the accumulation levels of $\mathrm{N}, \mathrm{N}-$ Dimethyltryptamine in micropropagated trees and in in vitro cultures of Mimosa tenuiflore. Nat Prod Res. 61-67.

[148] Nunes OD, Pereira RD (2008) "Regression of Herpes viral infection symptoms using melatonin and Sb-73: Comparison with Acyclovir." Journal of Pineal Research. 44(4): 373-378.

[149] Oba S, Nakamura K, Sahashi Y, Hattori A, Nagata C (2008) Consumption of vegetables alters morning urinary 6sulfatoxymelatonin concentration. J Pineal Res. 45: 17-23.

[150] Okazaki M, Ezura H (2009) Profiling of melatonin in the model tomato (Solanum lycopersicum L.) cultivar Micro-Tom. J. Pineal Res. 46:338-343. (Doi:10.1111/j.1600-079X.2009.00668.x).

[151] Pandi-Perumal SR, Srinivasan V, Maestroni GJM. Cardinali DP, Poeggeler B, Hardeland R (2006) Melatonin Nature's most versatile biological signal. FEBS Journal. $273: 2813-2838$.

[152] Park WJ, Back K (2012) Melatonin promotes seminal root elongation and root growth in transgenic rice after germination. J. Pineal Res. 53:385-389. (Doi:10.1111/j.1600079X.2012.01008.x).

[153] Park WJ (2011) Melatonin as an endogenous plant regulatory signal: Debates and perspectives. J. Plant Biology. 54:143-149. (DOI 10.1007/s12374-011-9159-6).

[154] Park S, Lee DE, Jang H, Byeon Y, Kim YS, Back K (2012) Melatonin-rich transgenic rice plants exhibit resistance to herbicide-induced oxidative stress. J Pineal Res. (Doi:10.1111/j.1600-079X.2012.01029.x).
[155] Peuhkuri K, Sihvola N, Korpela R (2012) Dietary factors and fluctuating levels of melatonin. Food and Nutrition Research. 56: 17252. (http://dx.doi.org/10.3402/fnr.v56i0.17252).

[156] Pelagio-Flores R， Muñoz-Parra E，Ortiz-Castro R， López-Bucio J (2012) Melatonin regulates Arabidopsis root system architecture likely acting independently of auxin signaling. J. Pineal. Res. 53: 279-288. (https://doi.org/10.1111/j.1600-079X.2012.00996.x).

[157] Perez-Llorca M, Muñoz P, Muller M, Munne-Bosch S (2019) Biosynthesis, metabolism and function of auxin, salicylic acid and melatonin in climacteric and non-climacteric fruits. Front. Plant Sci. 10: 1-10. (https://doi.org/10.3389/fpls.2019.00136).

[158] Pérez-Llamas F, Hernández-Ruiz J, Cuesta A, Zamora S, Arnao MB (2020) Development of a phytomelatonin-rich extract from cultured plants with excellent biochemical and functional properties as an alternative to synthetic melatonin. Antioxidants. 9: 158. (doi:10.3390/antiox9020158).

[159] Pereira N, Naufel MF, Ribeiro EB, Tufik S, Hachul H (2020) Influence of dietary sources of melatonin on sleep quality: A review. Journal of Food Science. 85 (1):5-13. (doi: 10.1111/17503841.14952).

[160] Posadzki PP, Bajpai R, Kyaw BM, Roberts NJ, Brzezinski A, Christopoulos GI, Divakar U, Bajpai S, Soljak M, Dunleavy G, Jarbrink K, Nang EEK, Soh CK, Car J (2018) Melatonin and health: An umbrella review of health outcomes and biological mechanisms of action. BMC Medicine. 16:18. ( DOI 10.1186/s12916-017-1000-8).

[161] Posmyk MM, Balabusta M, Wieczorek M et al., (2009) Melatonin applied to cucumber (Cucumis sativus L.) seeds improves germination during chilling stress. J. Pineal Res. 2009; 46:214 223.

[162] Posmyk MM, Kuran H, Marciniak K et al., (2008) Pre-sowing seed treatment with melatonin protects red cabbage seedlings against toxic copper ion concentrations. J Pineal Res. 45:24-31.

[163] Posmyk MM, Kuran H, Marciniak K, Janas KM (2008) Pre sowing seed treatment with melatonin protects red cabbage seedlings against toxic copper ion concentrations. J. Pineal Res. 45: 24-31. (https://doi.org/10.1111/j.1600-079X.2008.00552.x).

[164] Posmyk MM, Balabusta M, Wieczorek M, Sliwinska E, Janas KM (2009) Melatonin applied to cucumber (Cucumis sativus L .) seeds improves germination during chilling stress. J. Pineal Res. 46: 214-223. (https://doi.org/10.1111/j.1600-079X.2008.00652.x).

[165] Posmyk MM, Janas KM (2009) Melatonin in plants. Acta Physiol Plant. 31:1-11. (DOI 10.1007/s11738-008-0213-z).

[166] Pothinuch P, Tongchitpakdee S (2011) Melatonin contents in mulberry (Morus spp.) leaves: Effects of sample preparation, cultivar, leaf age and tea processing. Food Chemistry 128: 415419.

[167] Ramakrishna A, Giridhar P, Sankar KU, Ravishankar GA (2012) Melatonin and serotonin profiles in beans of Coffea species. J Pineal Res. 52: 470-6.

[168] Reiter RJ, Tan DX, Burkhardt S, Manchester LC (2001) Melatonin in plants. Nutr Rev. 59:286-290.

[169] Reiter RJ, Manchester LC, Tan DX (2005) Melatonin in walnuts: Influence on levels of melatonin and total antioxidant capacity of blood. Nutrition. 21:920-4.

[170] Reiter RJ, Tan DX, Zhou Z, Cruz M, Fuentes-Broto L, Galano A (2015) Phytomelatonin: Assisting plants to survive and thrive. Molecules. 20: 7396-7437. (doi:10.3390/molecules20047396).

[171] Reiter RJ, Tan DX (2002) Melatonin an antioxidant in edible plants. Ann. N.Y. Acad. Sci. 957: 341-344.

[172] Reiter RJ, Mayo JC, Tan DX, Sainz RM, Alatorre-Jimenez M, Qin L (2016) Melatonin as an antioxidant: Under promises but over delivers. J. Pineal Res. 61: 253-278. (https://doi.org/10.1111/jpi.12360).

[173] Reiter RJ, Abreu-Gonzalez P, Marik PE, Dominguez-Rodriguez A (2020) Therapeutic algorithm for use of melatonin in patients with COVID-19. Front. Med. 7:226. (doi: 10.3389/fmed.2020.00226).

[174] Reiter RJ, Tan DX, Leon J, Kilic U, Kilic E (2005) When melatonin gets on your nerves: Its beneficial actions in experimental models of stroke. Experimental Biology and Medicine. 230:104-117. 
[175] Reiter RJ, Manchester LC,Tan DX (2005) "Melatonin in walnuts: Influence on levels of melatonin and total antioxidant capacity of blood." Nutrition. 21(9): 920-924.

[176] Reiter RJ, Tan DX (2002) "Melatonin: An antioxidant in edible plants." Annual New York Academy of Science. 957: 341-344.

[177] Salehi B, Sharopov F, Fokou PVT, Kobylinska A, de Jonge L, Tadio K, Sharifi-Rad J, Posmyk MM, Martorell M, Martins N, Iriti M (2019) Melatonin in medicinal and food plants: Occurrence, bioavailability, and health potential for humans. Cells. 8(681):2-23. (doi:10.3390/cells8070681).

[178] Sanchez-Barcelo EJ, Mediavilla MD, Vriend J, Reiter RJ (2016) Constitutive photomorphogenesis protein 1 (COP1) and COP9 signalosome, evolutionarily conserved photomorphogenic proteins as possible targets of melatonin. J. Pineal Res. 1: 41-51. (https://doi.org/10.1111/jpi.12340).

[179] Sarrou E, Chatzopoulou P, Dimassi-Theriou K, Therios I, Koularmani A (2015) Effect of melatonin, salicylic acid and gibberellic acid on leaf essential oil and other secondary metabolites of bitter orange young seedlings. J. Essent. Oil Res. 27: 487-496. (https://doi.org/10.1080/10412905.2015.1064485).

[180] Sarropoulou VN, Therios IN, Dimassi-Theriou KN (2012) Melatonin promotes adventitious root regeneration in in vitro shoot tip explants of the commercial sweet cherry rootstocks CAB-6P (Prunus cerasus L.), Gisela 6 (P. cerasus · P. canescens), and MxM 60 (P. avium . P. mahaleb). J. Pineal Res. 52:38-46. (Doi:10.1111/j.1600-079X.2011.00914.x).

[181] Shanmugaraj B, Malla A, Phoolcharoen W (2020) Emergence of novel coronavirus 2019-nCoV: Need for rapid vaccine and biologics development. Pathogens. 9:148. (doi:10.3390/pathogens 9020148). (www.mdpi.com/journal/pathogens).

[182] Shi H, Chan Z (2014) The Cysteine2/Histidine2-type transcription factor ZINC FINGER OF ARABIDOPSIS THALIANA 6activated C-REPEAT-BINDING FACTOR pathway is essential for melatonin-mediated freezing stress resistance in Arabidopsis. J Pineal Res. 57:185-191.

[183] Shi H, Jiang C, Ye T et al., (2015) Comparative physiological, metabolomic, and transcriptomic analyses reveal mechanisms of improved abiotic stress resistance in bermudagrass [Cynodon dactylon (L). Pers.] by exogenous melatonin. J Exp Bot. 66:681694.

[184] Shin MD, Shukla S, Chung YH, Beiss V, Chan SK, OrtegaRivera OA, Wirth DM, Chen A, Sack M, Pokorski JK, Steinmetz NF (2020) COVID-19 vaccine development and a potential nanomaterial path forward. Nature Nanotechnology. 15:646-655

[185] Shneider A, Kudriavtsev A, Vakhrusheva A (2020) Can melatonin reduce the severity of COVID-19 pandemic?. International Reviews of Immunology. 39:(4):153-1. （ DOI: 10.1080/08830185.2020.1756284).

[186] Shereen MA, Khan S, Kazmi A, Bashir N, Siddique R (2020) COVID-19 infection: Origin, transmission, and characteristics of human coronaviruses. Journal of Advanced Research. 24 : 91-98.

[187] Shukla MR, Bajwa VS, Freixas-Coutin JA, Saxena PK (2021) Salt stress in Arabidopsis thaliana seedlings: Role of indoleamines in stress alleviation. Melatonin Res. 4 (1): 70-83. ( doi: 10.32794/mr11250082).

[188] Simopoulos AP, Tan DX, Manchester LC, Reiter RJ (2005) Purslane: A plant source of omega-3fatty acids and melatonin. J Pineal Res. 39:331-2.

[189] Sliwiak J, Dauter Z, Jaskolski M (2016) Crystal structure of Hyp1, a Hypericum perforatum PR-10 protein, in complex with melatonin. Front. Plant Sci. 7: 1-10. (https://doi.org/10.3389/fpls.2016.00668).

[190] Stege PW, Sombra LL, Messina G, Martinez LD, Silva MF (2010) Determination of melatonin in wine and plant extracts by capillary electrochromatography with immobilized carboxylic multi-walled carbon nanotubes as stationary phase. Electrophoresis. 31: 2242-8.

[191] Steward FC, Kent AE, Mapes MO (1967) Growth and organization in cultured cells: Sequential and synergistic effects of growth-regulating substances. Ann. N. Y. Acad. Sci. 144: 326334. (https://doi.org/10.1111/j.1749-6632.1967.tb34028.x).
[192] Stutte GW (2015) Commercial transition to leds: A pathway to high-value products. Hort Science. 50: 1297-1300.

[193] Sturtz M, Cerezo AB, Cantos-Villar E, Garcia-Parrilla MC (2011) Determination of the melatonin content of different varieties of tomatoes (Lycopersicon esculentum) and strawberries (Fragaria ananassa). Food Chem. 127: 1329-34.

[194] Sugden D (1989) Melatonin biosynthesis in the mammalian pineal gland. Experientia. 45:922-32.

[195] Sun QQ, Zhang N, Wang J et al., (2015) Melatonin promotes ripening and improves quality of tomato fruit during postharvest life. J Exp Bot. 66:657.

[196] Szafranska K, Glinska S, Janas KM (2013) Ameliorative effect of melatonin on meristematic cells of chilled and re-warmed Vigna radiata roots. Biol Plant. 57:91-96.

[197] Tal O, Haim A, Harel O, Gerchman Y (2011) Melatonin as an antioxidant and its semi-lunar rhythm in green macroalga Ulva sp. Journal of Experimental Botany. 62(6): 1903-1910.

[198] Tan DX, Manchister LC, Helton P et al., (2007) Phytoremediative capacity of plants enriched with melatonin. Plant Signal Behav. 2:514-516

[199] Tan DX, Zanghi BM, Manchester LC, Reiter, RJ (2014) Melatonin identified in meats and other food stuffs: Potentially nutritional impact. Journal of Pineal Research. 57(2): 213-218. (https://doi.org/10.1111/jpi.12152).

[200] Tan DXLC, Manchester MP, Terron LJ, Flores A, Reiter RJ (2007). "One molecule, many derivatives: A never-ending interaction of melatonin with reactive oxygen and nitrogen species?." Journal of Pineal Research. 42(1): 28-42.

[201] Tan DX, Hardeland R (2020) Potential utility of melatonin in deadly infectious diseases related to the overreaction of innate immune response and destructive inflammation: Focus on COVID-19. Melatonin Res. 3: 120-143.

[202] Tan DX, Chen LD, Poeggeler B, Manchester LC, Reiter RJ (1993) Melatonin: A potent, endogenous hydroxyl radical scavenger. Endocrine J. 1:57-60.

[203] Tan DX, Hardeland R, Manchester LC, Korkmaz A, Ma S, Rosales-Corral S, Reiter RJ (2011) Functional roles of melatonin in plants, and perspectives in nutritional and agricultural science. Journal of Experimental Botany. 63(2): 577-597. (https://doi.org/10.1093/jxb/err256).

[204] Tan DX, Hardeland R, Manchester LC, Paredes SD, Korkmaz A, Sainz RM, Mayo JC, Fuentes-Broto L,Reiter RJ (2010) The changing biological roles of melatonin during evolution: from an antioxidant to signals of darkness, sexual selection and fitness. Biol. Rev. 85: 607-623. 607. (doi: 10.1111/j.1469185X.2009.00118.x).

[205] Tekbas OFR, Ogur A, Korkmaz A, Kilic, Reiter RJ (2008) "Melatonin as an antibiotic: New insights into the actions of this ubiquitous molecule." Journal of Pineal Research. 44(2): 222-226.

[206] Tengattini S, Reiter RJ, Tan DX, Terron MP, Rodella LF, Rezzani R (2008) "Cardiovascular diseases: Protective effects of melatonin." Journal of Pineal Research. 44(1): 16-25.

[207] Tettamanti C, Cerabolini B, Gerola P (2000) Melatonin identification in medicinal plants. Acta Phytother. 3:137-44.

[208] Tiryaki I, Keles H (2012) Reversal of the inhibitory effect of light and high temperature on germination of Phacelia tanacetifolia seeds by melatonin. J. Pineal Res. 52: 332-339. (https://doi.org/10.1111/j.1600-079X.2011.00947.x).

[209] Uchendu EE, Shukla R, Reed BM et al., (2013) Melatonin enhances the recovery of cryopreserved shoot tips of American elm (Ulmus americana L.). J Pineal Res. 55:435-442.

[210] Ursing C, Wikner J, Brismar K, Rojdmark S (2003) Caffeine raises the serum melatonin level in healthy subjects: An indication of melatonin metabolism by cytochrome P450(CYP)1A2. J Endocrinol Invest. 26: 403-6.

[211] Van Tassel DL, O’Neill S (2001) Putative regulatory molecules in plants: Evaluating melatonin. J. Pineal Res. 31:1-7.

[212] Van Tassel DL, O'Neill S (1993) "Melatonin: identification of a potential dark signal in plants." in Plant Physiology. vol. 102, supplement 1 , article 659 . 
[213] Van Tassel DL, Roberts NJ, O'Neill SD (1995) Melatonin from higher plants: Isolation and identification of $\mathrm{N}$-acetyl-5methoxytryptamine. Plant Physiol. 108(2):101.

[214] Van Tassel DL, Roberts NJ, Lewy A, O’Neill SD (2001) Melatonin in plant organs. J Pineal Res. 31:8-15.

[215] Venkatramanujam S (2011) Therapeutic potential of melatonin and its analogs in Parkinson's disease: focus on sleep and neuroprotection. Ther Adv Neurol Disord. 4(5):297-317.

[216] Vijayalaxmi R, Thomas CR Jr, Reiter RJ, Herman TS (2002) Melatonin: From basic research to cancer treatment clinics. [review]. J Clin Oncol. 20:2575-2601.

[217] Vlachou M, Siamidi A, Dedeloudi A, Konstantinidou SK, Papanastasiou IP (2021) Pineal hormone melatonin as an adjuvant treatment for COVID-19 (Review). International Journal of Molecular medicine. 47 (47). (DOI: 10.3892/ijmm.2021.4880).

[218] Weeda S, Zhang N, Zhao X, Ndip G, Guo Y, Buck GA, Fu C, Ren S (2014) Arabidopsis transcriptome analysis reveals key roles of melatonin in plant defense systems. PLoS One. 9: e93462. (https://doi.org/10.1371/journal.pone.0093462).

[219] Wei J, Li DX, Zhang JR, Shan C, Rengel Z, Song ZB, Chen Q (2018) Phytomelatonin receptor PMTR1-mediated signaling regulates stomatal closure in Arabidopsis thaliana. J. Pineal Res. 65: 1-13. (https://doi.org/10.1111/jpi.12500).

[220] Wei W, Li Q, Chu Y-N et al., (2015) Melatonin enhances plant growth and abiotic stress tolerance in soybean plants. J Exp Bot. 66:695-707.

[221] Wen D, Gong B, Sun S, Liu S, Wang X, Wei M, Yang F, Li Y, Shi Q (2016) Promoting roles of melatonin in adventitious root development of Solanum lycopersicum L. by regulating auxin and nitric oxide signalling. Front. Plant Sci. 7. (https://doi.org/10.3389/fpls.2016.00718).

[222] West KE, Jablonski MR, Warfield B, Cecil KS, James M, Ayers MA, Maida J, Bowen C, Sliney DH, Rollag MD, Hanifin JP, Brainard GC (2011) Blue light from light-emitting diodes elicits a dose-dependent suppression of melatonin in humans. J. Appl. Physiol. 110: 619-626. (https://doi.org/10.1152/japplphysiol.01413.2009).

[223] Wolf K, Kolar J, Witters E, van Dongen W, van Onckelen H, Machackova I (2001) Daily profile of melatonin levels in Chenopodium rubrum L. depends on photoperiod. J. Plant Physiol. 158: 1491-1293.

[224] Wu YH, Swaab DF (2005). "The human pineal gland and melatonin in aging and Alzheimer's Disease. J. Pineal Research. 38(3): 145-152.

[225] Wu F, Zhao S, Yu B, Chen YM, Wang W, Song ZG, Hu Y, Tao ZW, Tian JH, Pei YY, Yuan ML, Zhang YL, Dai FH, Liu Y, Wang QM, Zheng JJ, Xu L, Holmes EC, Zhang YZ (2020a) A new coronavirus associated with human respiratory disease in China. Nature. 579 (7798) 265-269.

[226] Wu YQ, Zou L, Yu X, Sun D, Li SB, Tang L, Yang JR, Chen XY, Wu YG, Fang H (2020b) Clinical effects of integrated traditional Chinese and western medicine on COVID-19: A systematic review. Shanghai J. Tradit. Chin. Med. 1-8.

[227] Xu Z, Shi LY, Wang J, Zhang L, Huang C, Zhang S, Liu P, Zhao H, Liu L, Zhu Y, Tai C, Bai T, Gao J, Song P, Xia J, Dong J, Zhao FS, Wang J (2020) Pathological findings of COVID-19 associated with acute respiratory distress syndrome. Lancet. Respir. Med. (https://doi.org/10.1016/S2213-2600(20)30076-X).

[228] Yang S, Zheng X, Xu Y, Zhou X (2002) Rapid determination of serum melatonin by ESI-MS-MS with direct sample injection. J. Pharm Biomed Anal. 30:781-90.

[229] Ye T, Hao YH, Yu L, Shi H, Reiter RJ, Feng YQ (2017) A simple, rapid method for determination of melatonin in plant tissues by UPLC coupled with high resolution orbitrap mass spectrometry. Front. Plant Sci. 8:64. (doi: 10.3389/fpls.2017.00064).

[230] Yin L, Wang P, Li M et al., (2013) Exogenous melatonin improves Malus resistance to Marssonina apple blotch. J. Pineal Res. $54: 426-434$
[231] Yu HS, Reiter RJ (1993) Melatonin: Biosynthesis, physiological effects, and clinical applications. Boca Raton, FL: CRC Press, 1993

[232] Yun AJ, Bazar KA, Lee PY (2004) "Pineal attrition, loss of cognitive plasticity, and onset of puberty during the teen years: Is it a modern maladaptation exposed by evolutionary displacement?". Medical Hypotheses. 63(6): 939-950.

[233] Zawilska JB, Skene DJ, Arendt J (2009) Physiology and pharmacology of melatonin in relation to biological rhythms. Pharmacological Reports. 61: 383-410.

[234] Zhang HJ, Zhang N, Yang RC, Wang L, Sun QQ, Li DB, Cao YY, Weeda S, Zhao B, Ren S, Guo YD (2014) Melatonin promotes seed germination under high salinity by regulating antioxidant systems, ABA and GA4 interaction in cucumber (Cucumis sativus L.). J. Pineal Res. 57: 269-279. (https://doi.org/10.1111/jpi.12167).

[235] Zhang J, Shi Y, Zhang X, Du H, Xu B, Huang B (2017) Melatonin suppression of heat-induced leaf senescence involves changes in abscisic acid and cytokinin biosynthesis and signaling pathways in perennial ryegrass (Lolium perenne L.). Environ. Exp. Bot. 138: 36-45. (https://doi.org/10.1016/j.envexpbot.2017.02.012).

[236] Zhang N, Sun Q, Li H, Li X, Cao Y, Zhang H, Zhao B (2016) Melatonin improved anthocyanin accumulation by regulating gene expressions and resulted in high reactive oxygen species scavenging capacity in cabbage. Front. Plant Sci. 7: 1-17. (https://doi.org/10.3389/fpls.2016.00197).

[237] Zhang N, Jiang YL, Li Y, Chen Q, Ye Y, Zhang Y, Luo Y, Sun B, Wang X, Tang H (2018) Effect of red and blue light on anthocyanin accumulation and differential gene expression in strawberry (Fragaria $\times$ ananassa). Molecules. 23: 1-17. (https://doi.org/10.3390/molecules23040820).

[238] Zhang N, Sun Q, Zhang H, Cao Y, Weeda S, Ren S, Guo YDD (2015) Roles of melatonin in abiotic stress resistance in plants. J. Exp. Bot. 66: 647-656. (https://doi.org/10.1093/jxb/eru336).

[239] Zhang Z, Hu Q, Liu Y, Cheng P, Cheng H, Liu W, Xing X, Guan Z, Fang W, Chen S, Jiang J, Chen F (2019) Strigolactone represses the synthesis of melatonin, thereby inducing floral transition in Arabidopsis thaliana in an FLC-dependent manner. J. Pineal Res. 67: 1-11. (https://doi.org/10.1111/jpi.12582).

[240] Zhao Y, Tan DX, Lei Q, Chen H, Wang L, Li Q, Gao Y, Kong J (2013) Melatonin and its potential biological functions in the fruits of sweet cherry. J. Pineal Res. 55: 79-88.

[241] Zhao Y, Qi LW, Wang WM et al., (2011) Melatonin improves the survival of cryopreserved callus of Rhodiola crenulata. J Pineal Res. 50:83-88.

[242] Zhao N, Sun Y, Wang DY et al., (2012) Effects of exogenous melatonin on nitrogen metabolism in cucumber seedlings under high temperature stress. 48:557-564.

[243] Zhang HJ, Zhang N, Yang RC et al., (2014) Melatonin promotes seed germination under high salinity by regulating antioxidant systems, ABA and GA4 interaction in cucumber (Cucumis sativus L.). J Pineal Res. 57:269-279.

[244] Zhang N, Zhao B, Zhang HJ et al., (2013) Melatonin promotes water-stress tolerance, lateral root formation, and seed germination in cucumber (Cucumis sativus L.). J Pineal Res. 54:15-23.

[245] Zhang R, Wang X, Ni L， Di X，Ma B， Niu S，Liu C，Reiter RJ (2020) COVID-19: Melatonin as a potential adjuvant treatment. Life Sci., 117583. (https://doi.org/10. 1016/j.lfs.2020.117583).

[246] Zhang D, Zhang B, Lv JT, Sa RN, Zhang XM, Lin ZJ (2020a) The clinical benefits of Chinese patent medicines against COVID-19 based on current evidence. Pharmacol. Res. 157:104882. (doi: 10.1016/j.phrs.2020.104882).

[247] Zhang E, Du RH, Li B, Zheng XS, Yang XL, Hu B, Wang YY, Xiao GF, Yan B, Shi ZL, Zhou P (2020b) Molecular and serological investigation of 2019-nCoV infected patients: Implication of multiple shedding routes. Emerging Microbes and Infections. 9: 386-89.

[248] Zhang R, Lib Y, Zhangc AL, Wangd Y, Molinae MJ (2020c) Identifying airborne transmission as the dominant route for the 
spread of COVID-19. Proc. Natl. Acad. Sci. USA. 117(26): 14857-14863.

[249] Zhou P, Yang XL, Wang XG, Hu B, Zhang L, Zhang W et al., (2020a) Discovery of a novel coronavirus associated with the recent pneumonia outbreak in humans and its potential bat origin. Nature. 579: 270-273. (doi: 10.1038/s41586-020-2012-7).

[250] Zhou P, Yang XL, Wang XG, Hu B, Zhang L, Zhang W et al., (2020b) A pneumonia outbreak associated with a new coronavirus of probable bat origin. Nature. 579: 270-273.

[251] Zhu N, Zhang D, Wang W et al., (2020) China novel coronavirus investigation research team. A novel coronavirus from patients with pneumonia in China 2019. N Engl J Med. 382:727-33.

[252] Ziaei A, Davoodian P, Dadvand H et al., (2020) Evaluation of the efficacy and safety of melatonin in moderately ill patients with
COVID-19: A structured summary of a study protocol for a randomized controlled trial. Trials. 21: 882 . (https://doi.org/10.1186/s13063-020-04737-w).

[253] Zimmermann RC, McDougle CJ, Schumacher M, Olcese J, Mason JW, Heninger GR et al., (1993) Effects of acute tryptophan depletion on nocturnal melatonin secretion in humans. J. Clin Endocrinol Metab. 76: 1160-4. (http://jcem.endojournals. org/content/76/5/1160.long)

[254] Zoratti L, Sarala M, Carvalho E, Karppinen K, Martens S, Giongo L, Häggman H, Jaakola L (2014) Monochromatic light increases anthocyanin content during fruit development in bilberry. BMC Plant Biol. 14: 1-10. (https://doi.org/10.1186/s12870-014-0377-1). 